\title{
Identification and transcriptomic profiling of genes involved in increasing sugar content during salt stress in sweet sorghum leaves
}

\author{
Na Sui ${ }^{*}$, Zhen Yang ${ }^{\dagger}$, Mingli Liu and Baoshan Wang ${ }^{*}$
}

\begin{abstract}
Background: Sweet sorghum is an annual C4 crop considered to be one of the most promising bio-energy crops due to its high sugar content in stem, yet it is poorly understood how this plant increases its sugar content in response to salt stress. In response to high $\mathrm{NaCl}$, many of its major processes, such as photosynthesis, protein synthesis, energy and lipid metabolism, are inhibited. Interestingly, sugar content in sweet sorghum stems remains constant or even increases in several salt-tolerant species.

Results: In this study, the transcript profiles of two sweet sorghum inbred lines (salt-tolerant M-81E and salt-sensitive Roma) were analyzed in the presence of $0 \mathrm{mM}$ or $150 \mathrm{mM} \mathrm{NaCl}$ in order to elucidate the molecular mechanisms that lead to higher sugar content during salt stress. We identified 864 and 930 differentially expressed genes between control plants and those subjected to salt stress in both M-81E and Roma strains. We determined that the majority of these genes are involved in photosynthesis, carbon fixation, and starch and sucrose metabolism. Genes important for maintaining photosystem structure and for regulating electron transport were less affected by salt stress in the M-81E line compared to the salt-sensitive Roma line. In addition, expression of genes encoding NADP ${ }^{+}$-malate enzyme and sucrose synthetase was up-regulated and expression of genes encoding invertase was down-regulated under salt stress in M-81E. In contrast, the expression of these genes showed the opposite trend in Roma under salt stress.
\end{abstract}

Conclusions: The results we obtained revealed that the salt-tolerant genotype M-81E leads to increased sugar content under salt stress by protecting important structures of photosystems, by enhancing the accumulation of photosynthetic products, by increasing the production of sucrose synthetase and by inhibiting sucrose decomposition.

Keywords: Transcriptomic profile, Sugar content, Photosynthesis, Salt stress, Sweet sorghum

\section{Background}

Soil salinity is not only one of the major factors leading to deterioration of the ecological environment but also a major abiotic stress in plant agriculture worldwide [1]. Salt stress involves a combination of osmotic stress and ionic stress that greatly affects plant growth and crop production [2]. Upon salt treatment, lots of the major processes within plants, such as photosynthesis, protein synthesis, energy metabolism and lipid metabolism are affected [3]. Salt treatment also regulates the expression level of many genes involved either directly or indirectly in plant protection [2]. In the past few decades, many

\footnotetext{
*Correspondence: suina800101@163.com; bswang.t@163.com

${ }^{\dagger}$ Equal contributors

Key Laboratory of Plant Stress Research, College of life science, Shandong Normal University, Jinan, Shandong 250014, PR China
}

efforts have been made to understand the molecular mechanisms of salt tolerance. Utilization of genes related to compatible solutes [4], ion transporters [5] and transcription factors [6] is regarded as a way to improve the salt tolerance of plants.

Sweet sorghum [Sorghum bicolor (L.) Moench] which originates from Africa is an annual C4 crop [7]. Sweet sorghum has a fast growth rate and high efficiency of biomass accumulation. It is consumed as a food source for humans and as livestock feed. In addition, it has been considered to be one of the most promising bio-energy crops [8], as the stalks are rich in fermentable sugars. The tolerance of sweet sorghum to salinity is thought to be high. However, there are salt-tolerant and saltsensitive genotypes of sweet sorghum. Salt-tolerant genotypes have a greater ability to exclude toxic ions and 
to store the absorbed toxic ions in the root cell vacuoles while maintaining high levels of $\mathrm{K}^{+}$uptake. As a result, the accumulation of $\mathrm{Na}^{+}$and $\mathrm{Cl}^{-}$in actively growing shoots and leaves may be limited. This mechanism can effectively prevent the photosynthetic apparatus of sweet sorghum from being damaged by $\mathrm{Na}^{+}$and $\mathrm{Cl}^{-}$. On the other hand, the ability to compartmentalize $\mathrm{Na}^{+}$within root cell vacuoles is lower in salt-sensitive genotypes [9], which results in a higher level of $\mathrm{Na}^{+}$accumulated in leaves. Due to this accumulation, the photosynthetic apparatus may be damaged by $\mathrm{Na}^{+}$and the photosynthesis will significantly decrease.

Interestingly, it has been shown that the brix of saltsensitive sweet sorghum decreases under salt stress. The brix of salt-tolerant species, on the other hand, stays stable or is even increased by salt stress [10-12]. As we know, the main source of carbon and energy in the sink tissues of sweet sorghum is sucrose. Several physiological processes play important roles in maintaining the high sugar content in stems of sweet sorghum. A) $\mathrm{CO}_{2}$ from the atmosphere is fixed in the mesophyll cells. Stalk sugar content accumulation of sweet sorghum depends on the synthesis and accumulation of photosynthetic products. The initial product of $\mathrm{CO}_{2}$ fixation is oxaloacetate (OAA). OAA is converted into a transportable form (malate) and is then transported to the bundle sheath. After a series reactions through the $\mathrm{C} 4$ pathway, 3-phosphoglycerate is produced which is then converted to triose phosphate (TP) [13]. B) Once TP has been produced, it either leaves the chloroplast via the triose phosphate translocator (TPT) in exchange for orthophosphate or it remains in the chloroplast stroma for the completion of the Calvin cycle or to be converted to starch [14]. C) TP in the cytoplasm can be converted to fructose-6-phosphate (Fru-6-P). Then, Fru-6-P can be further converted to sucrose by sucrose phosphate phosphatase (SPS, EC3.1.2.24) or to UDP-glucose (UDP-Glu). UDP-Glu is used as substrates in sucrose synthesis, a reaction catalyzed by sucrose synthase (SS, EC2.4.1.13). Sucrose can be decomposed into glucose and fructose by invertase (INV, EC3.2.1.26) in vacuole. D) Six sucrose transporters (SUT1-6) have been reported in monocots [15], which are located in the plasma membranes of sieve elements and companion cells, or in tonoplasts of storage cells. SUTs have been reported to play an important role in the re-distribution of sucrose [16].

Although there are numerous studies on the response mechanism of sweet sorghum to salt stress, most of which are restricted to the eco-physiological level or to the study of a single pathway. The physiological and molecular mechanisms of increasing sugar content in salt-tolerant sweet sorghum species under salt stress is remain unclear. In recent years, with the increasing availability of sequence data, expression profiling has been used to identify genes involved in the adaptive responses abiotic stresses. A common strategy to identify genes related to salt stress is using a comparative study of different genotypes or cultivars in the tolerance to the abiotic stress [17-19]. Comparisons between salt-sensitive and salt-tolerant genotypes of model and non-model plant species have been reported, including Arabidopsis [19], rice [18, 20], olive [17], populus [21] and tomato [22]. In the present study, the transcriptomes of salt-sensitive and a salt-tolerant sweet sorghum inbred lines were analyzed by high-throughput Illumina RNA-sequencing (RNA-seq). By comparing the transcriptomes of a salt-sensitive and a salt-tolerant sweet sorghum inbred line under salt stress, we identified 864 and 930 differentially expressed genes (DEGs) between control plants and those subjected to salt in $\mathrm{M}-81 \mathrm{E}$ and Roma, respectively. Results of this study should provide further insight into the complex regulatory networks underlying the mechanism of higher sugar content under salt stress in sweet sorghum.

\section{Results}

\section{Effects of salt stress on growth parameters}

After treated with $50 \mathrm{mM} \mathrm{NaCl}$ for 7 days, there was no significant difference in M-81E (Fig. 1a), while growth of Roma was significantly inhibited (Fig. 1b). In the presence of $150 \mathrm{mM} \mathrm{NaCl}$, the growth of both genotypes was inhibited, but it was more severe in Roma. Leaf length of $\mathrm{M}-81 \mathrm{E}$ was not affected by $50 \mathrm{mM} \mathrm{NaCl}$ treatment, but slightly decreased $15.6 \%$ at $150 \mathrm{mM} \mathrm{NaCl}$ treatment. Leaf length of Roma decreased $27.2 \%$ at $50 \mathrm{mM} \mathrm{NaCl}$ treatment and $41.6 \%$ at $150 \mathrm{mM} \mathrm{NaCl}$ treatment (Additional file 1: Figure S1). Leaf numbers of $\mathrm{M}-81 \mathrm{E}$ and Roma were not affected by $50 \mathrm{mM} \mathrm{NaCl}$, but decreased 23.2 and $31.3 \%$, respectively, when treated with $150 \mathrm{mM} \mathrm{NaCl}$ (Additional file1: Figure S1). Fresh weight (FW) of leaves of both genotypes gradually decreased with an increase in $\mathrm{NaCl}$ concentration. The reductions were more severe at $150 \mathrm{mM}$, particularly for Roma (Additional file 2: Figure S2) in which values decreased 43.1 and $68.6 \%$ for 50 and $150 \mathrm{mM} \mathrm{NaCl}$ concentrations, respectively. Dry weight (DW) of leaves also decreased with an increase in $\mathrm{NaCl}$ concentration. The highest reduction in Roma was $62.9 \%$ at $150 \mathrm{mM} \mathrm{NaCl}$ (Additional file 2: Figure S2). There was no significant effect on water content during $\mathrm{NaCl}$ treatment. (Additional file 2: Figure S2).

\section{Effects of salt stress on ion concentration}

After treated with $50 \mathrm{mM} \mathrm{NaCl}$ for 7 days, there were no significant changes in $\mathrm{Na}^{+}$concentrations in leaves of both genotypes compared to control plants (Additional file 3: Figure S3). When a higher concentration of salt (150 mM) was applied, $\mathrm{Na}^{+}$concentration increased significantly, especially for Roma. The $\mathrm{K}^{+}$concentration in 


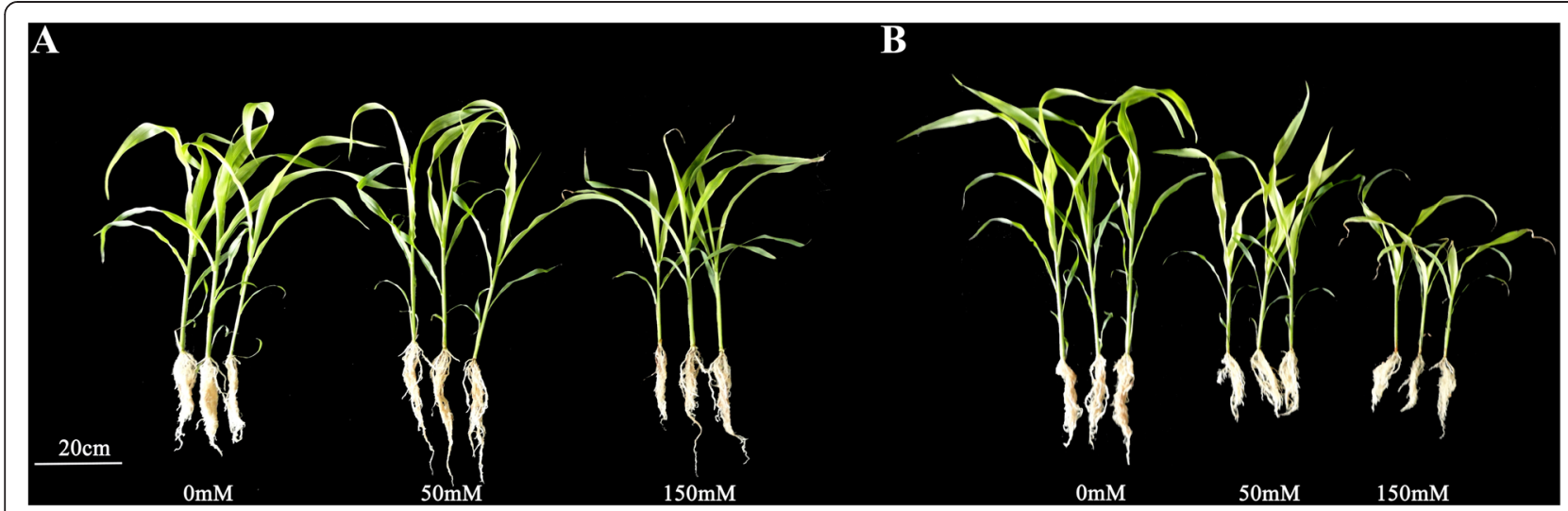

Fig. 1 The phenotype of M-81E (a) and Roma (b) treated with different concentrations of $\mathrm{NaCl}(0,50$ and $150 \mathrm{mM})$ for 7 days

leaves gradually decreased in response to $\mathrm{NaCl}$. At the $150 \mathrm{mM} \mathrm{NaCl}$ treatment, $\mathrm{K}^{+}$concentration of $\mathrm{M}-81 \mathrm{E}$ and Roma decreased 30.6 and $41.6 \%$, respectively (Additional file 3: Figure S3). The $\mathrm{K}^{+} / \mathrm{Na}^{+}$ratio in leaves of $\mathrm{M}-81 \mathrm{E}$ increased under $50 \mathrm{mM} \mathrm{NaCl}$ treatment and then decreased when treated by $150 \mathrm{mM} \mathrm{NaCl}$. While the $\mathrm{K}^{+} / \mathrm{Na}^{+}$ratio in leaves of Roma decreased under the $\mathrm{NaCl}$ treatment. At $150 \mathrm{mM} \mathrm{NaCl}$ treatment, the $\mathrm{K}^{+} / \mathrm{Na}^{+}$ ratio in Roma decreased by a factor of fourteen times (Additional file 3: Figure S3).

\section{Effects of salt stress on PSII photochemical efficiency}

In both genotypes the potential efficiency of PSII photochemistry $(\mathrm{Fv} / \mathrm{Fm})$ was reduced with increasing $\mathrm{NaCl}$ concentration (Fig. 2). After treated with $50 \mathrm{mM} \mathrm{NaCl}$ for 7 days, Fv/Fm of $\mathrm{M}-81 \mathrm{E}$ and Roma decreased 3.6 and $11.1 \%$, respectively. For $150 \mathrm{mM} \mathrm{NaCl}, \mathrm{Fv} / \mathrm{Fm}$ of M-81E and Roma decreased 4.2 and $20.8 \%$, respectively (Fig. 2). The actual PSII efficiency (ФPSII) decreased in both genotypes after treated with $\mathrm{NaCl}$. ФPSII of M-81E treated with 50 and $150 \mathrm{mM} \mathrm{NaCl}$ decreased 10.7 and $14.4 \%$, respectively. In Roma, ФPSII decreased 36.6 and $50.7 \%$ for 50 and $150 \mathrm{mM} \mathrm{NaCl}$ treatment, respectively.

\section{Effects of salt stress on chlorophyll content}

The effects of increasing level of $\mathrm{NaCl}$ salinity on chlorophyll contents in the two genotypes were determined after 7 day exposure to salinity (Fig. 3). Chlorophyll content in M-81E was not changed significantly by $50 \mathrm{mM} \mathrm{NaCl}$ but decreased $46.5 \%$ under $150 \mathrm{mM} \mathrm{NaCl}$ treatment. On the other hand, in Roma, chlorophyll content decreased gradually with the increasing $\mathrm{NaCl}$ treatments. Chlorophyll content of Roma treated with 50 and $150 \mathrm{mM} \mathrm{NaCl}$ decreased 37.6 and $68.4 \%$, respectively.

\section{Effects of salt stress on photosynthesis}

There were no significant changes in photosynthetic rate, stomatal conductance and intercellular $\mathrm{CO}_{2}$ concentration in M-81E under salt stress. However, photosynthesis in Roma was significantly influenced by salt stress (Fig. 4). The photosynthetic rate of Roma was inhibited after treated with $\mathrm{NaCl}$ for 7 days. The reduction percentage of photosynthetic rate of Roma was 45.1 and $67.5 \%$ for $50 \mathrm{mM}$ and $150 \mathrm{mM} \mathrm{NaCl}$ treatment, respectively. Stomatal conductance of Roma decreased 35.5 and $60.9 \%$ after treated with $50 \mathrm{mM}$ and $150 \mathrm{mM}$ $\mathrm{NaCl}$, respectively. Intercellular $\mathrm{CO}_{2}$ concentration of

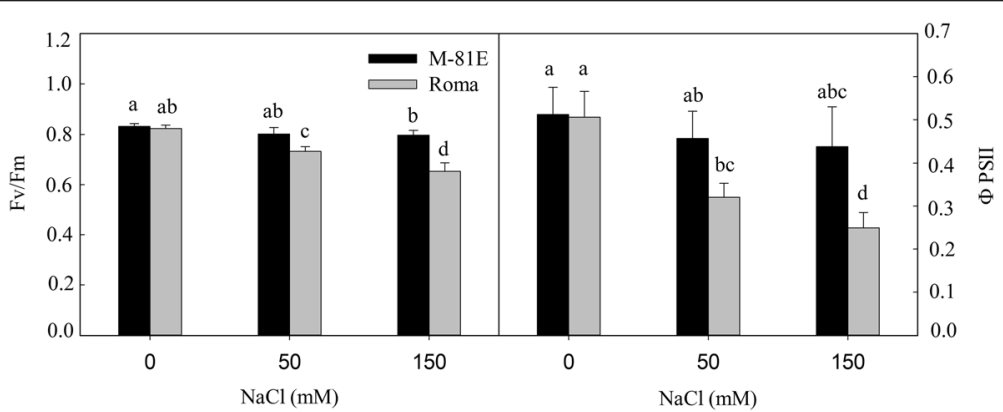

Fig. 2 Effect of salt stress $(0,50$ and $150 \mathrm{mM})$ on Fv/Fm and DPSII in leaves of M-81E and Roma. Fv/Fm and DPSII were measured after treated with $\mathrm{NaCl}$ for 7 days. Values are means \pm SD of five measurements for each of five plants. Bars with the different letters are significantly different at $p=0.05$ according to Duncan's multiple range test. Bars with same letter are not significantly different 


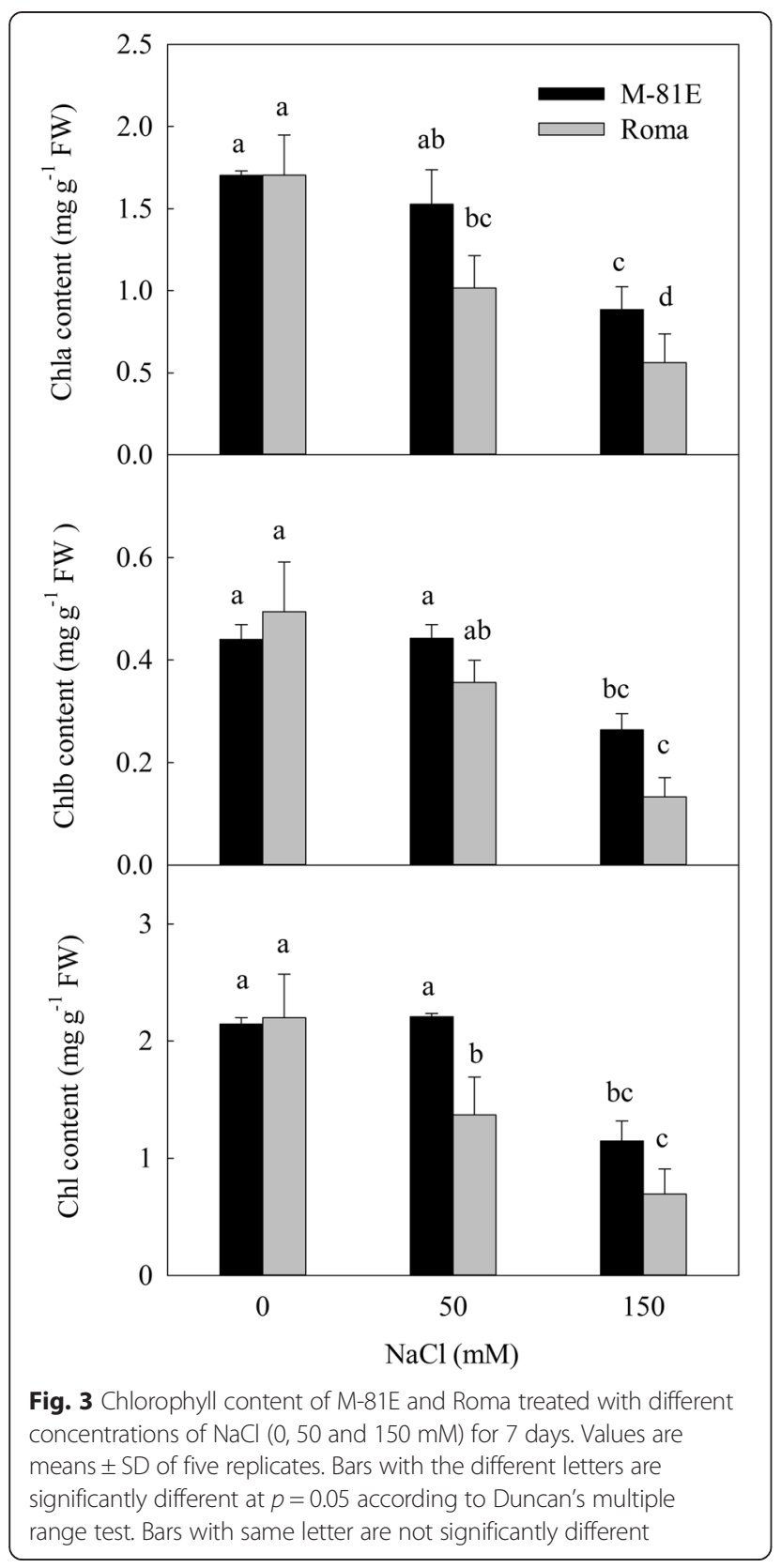

Roma decreased $23.0 \%$ under $50 \mathrm{mM} \mathrm{NaCl}$. While after treated with $150 \mathrm{mM} \mathrm{NaCl}$ for 7 days, the intercellular $\mathrm{CO}_{2}$ concentration of Roma increased $3.9 \%$.

\section{Effects of salt stress on sugar content}

The effects of increasing level of $\mathrm{NaCl}$ salinity on sugar contents in the two genotypes were determined after 7 days exposure to salinity. After treated for 7 days, the sugar content of M-81E increased 15.6 and $99.7 \%$ under $50 \mathrm{mM}$ and $150 \mathrm{mM} \mathrm{NaCl}$, respectively. While, there was no significant change in sugar content of Roma under $50 \mathrm{mM} \mathrm{NaCl}$. Under $150 \mathrm{mM} \mathrm{NaCl}$, the sugar content of Roma decreased 30.5 \% (Fig. 5).

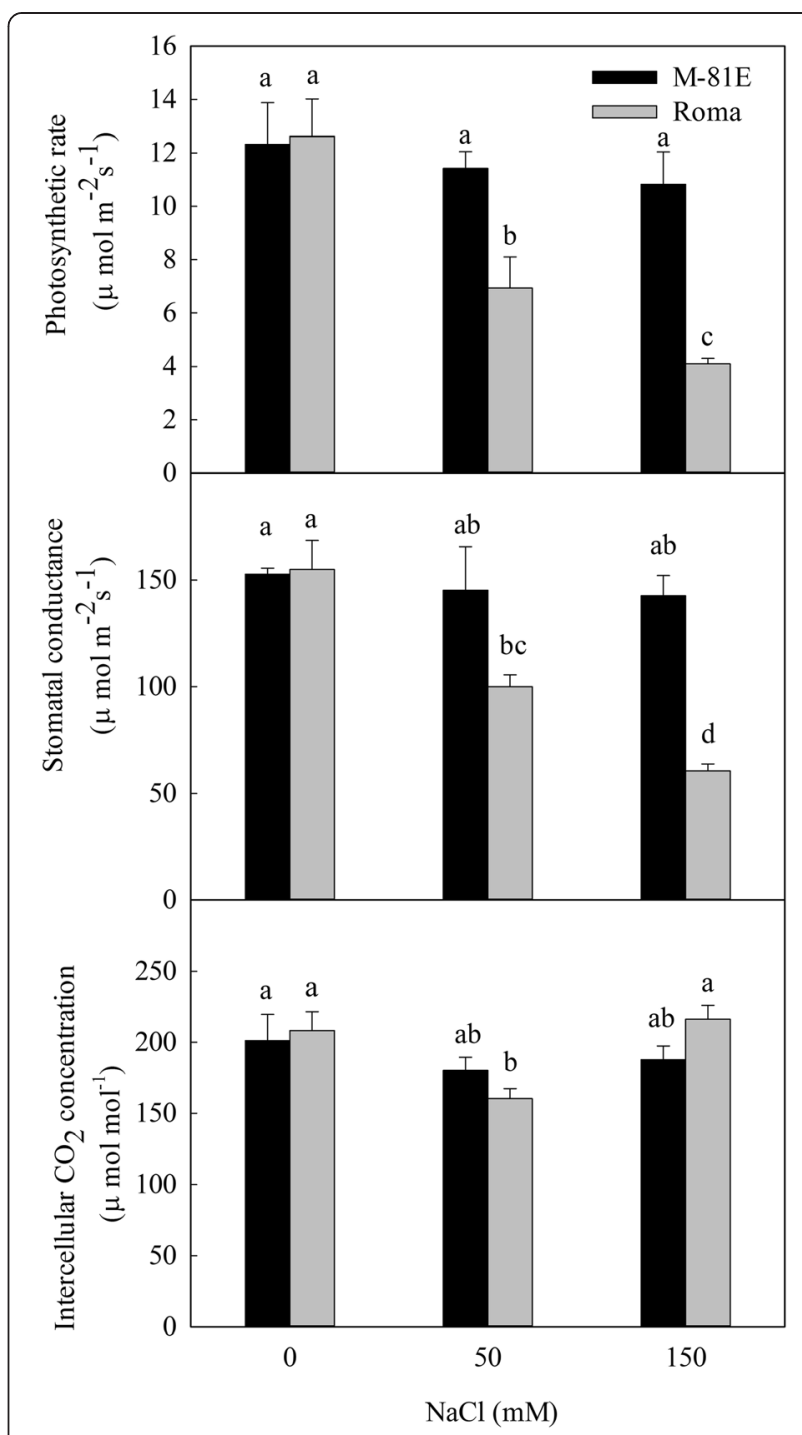

Fig. 4 Photosynthetic rate, stomatal conductance and intercellular $\mathrm{CO}_{2}$ concentration of $\mathrm{M}-81 \mathrm{E}$ and Roma treated with different concentrations of $\mathrm{NaCl}(0,50$ and $150 \mathrm{mM})$ for 7 days. Values are means \pm SD of five replicates. Bars with the different letters are significantly different at $p=0.05$ according to Duncan's multiple range test. Bars with same letter are not significantly different

\section{Sequencing output and assembly}

In order to investigate the molecular mechanisms of high sugar content under salt stress in sweet sorghum, libraries (MC, MS, RC and RS) were designed for RNAseq. MC and MS libraries were used for leaves of M-81E treated with $0 \mathrm{mM}$ and $150 \mathrm{mM} \mathrm{NaCl}$, respectively. RC and RS libraries were used for leaves of Roma treated with $0 \mathrm{mM}$ and $150 \mathrm{mM} \mathrm{NaCl}$, respectively. In total, 78.41 million reads were generated. After trimming adapters and filtering out low quality reads, more than 67.08 million clean reads were retained for assembly and further analysis. Among all the reads, more than $94 \%$ had Phred-like quality scores at the Q30 level (an error 


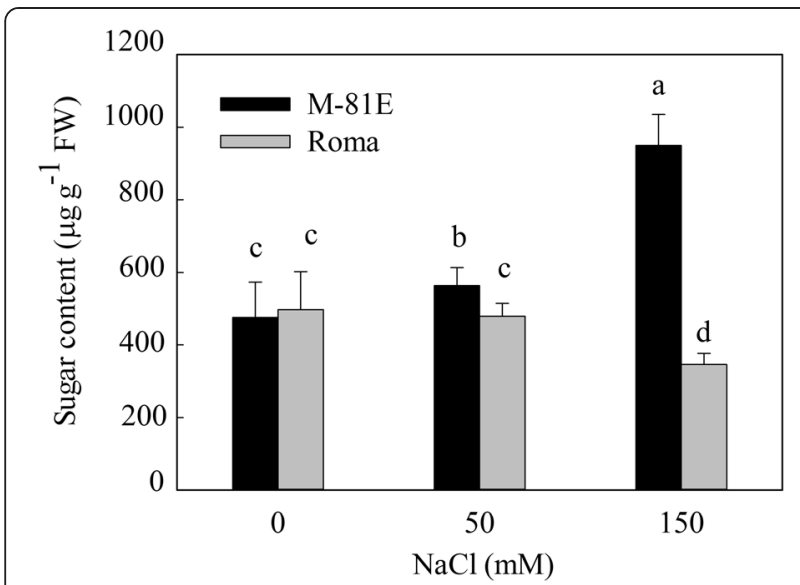

Fig. 5 Sugar content of M-81E and Roma treated with different concentrations of $\mathrm{NaCl}(0,50$ and $150 \mathrm{mM})$ for 7 days. Values are means \pm SD of five replicates. Bars with the different letters are significantly different at $p=0.05$ according to Duncan's multiple range test

probability of $0.1 \%$ ) (Additional file 4: Table S1). All these data showed that the throughput and sequencing quality were high enough for further analysis. The reads produced in this study have been deposited in the National Center for Biotechnology Information (NCBI) SRA database and accession number was shown in "Availability of supporting data".

\section{Exploration of DEGs in response to salt stress}

In the absence of salt, 3342 genes showed differential expression levels when comparing M-81E vs. Roma. While in the presence of salt, the DEGs between them were 2265. For M-81E, 864 genes were differentially expressed between control plants and those subjected to salt. Among these DEGs, 236 genes were up-regulated in leaves under salt stress. For Roma, 930 genes were differentially expressed between control plants and those subjected to salt. Among these DEGs, 442 genes were up-regulated in leaves under salt stress (Fig. 6). All of these DEGs were selected for further analysis.

\section{Functional categorization of stress-regulated genes Functional classification by GO}

In order to assign functional information to the DEGs between control plants and those treated with $\mathrm{NaCl}$, Gene Ontology (GO) [23] analysis was carried out. This analysis provides a dynamic, controlled vocabulary and also hierarchical relationships for the representation of information on biological processes, molecular function, and cellular components, forming a coherent annotation of various gene products [23]. In M-81E, there were 812 unique transcripts assigned to 48 level-2 GO terms, which were summarized under three main GO categories, including 13 for cellular component, 12 for molecular

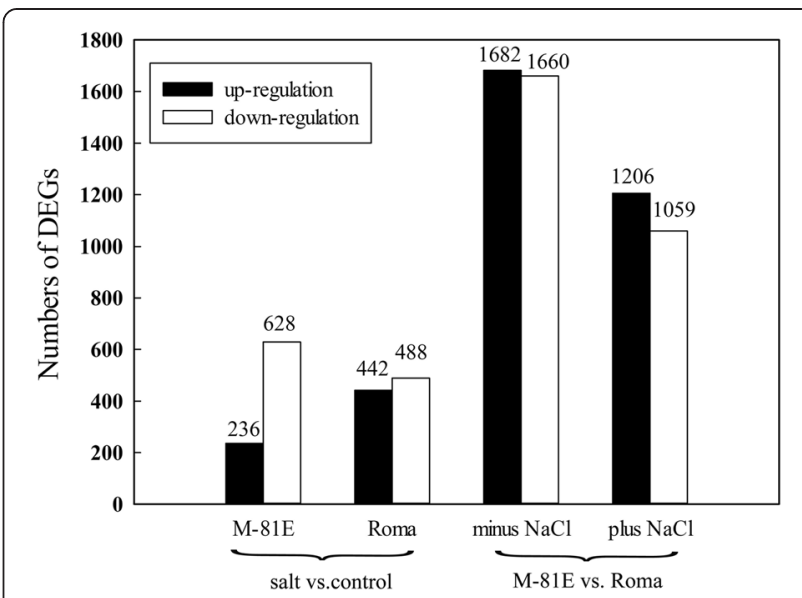

Fig. 6 Numbers of DEGs of different genotypes affected by salt stress

function and 23 for biological process, respectively. In Roma, there were 878 unique transcripts assigned to 47 level-2 GO terms including 13 for cellular component, 12 for molecular function and 22 for biological process, respectively. For the cellular group, in both $\mathrm{M}-81 \mathrm{E}$ and Roma, the most represented category was cell part, cell and organelle. For molecular function, the category of binding was the most represented GO term, followed second by the category of catalytic activity. Regarding biological process, NCBI UniGene for cellular process and metabolic process were highly represented (Fig. 7).

\section{Functional classification by COG}

In addition, all the DEGs were subjected to a search against the Clusters of Orthologous Groups (COG) [24] classification. Among the 864 DEGs, 349 sequences showed a COG classification in M-81E (Additional file 5: Figure S4A). Among the 25 COG categories, the cluster for "general function prediction only" was the largest group, followed by "secondary metabolites biosynthesis, transport and catabolism", "amino acid transport and metabolism", "carbohydrate transport and metabolism" and "transcription". The categories "chromatin structure and dynamics", "extracellular structure" and "nuclear structure" had no corresponding genes. The 360 sequences of the 930 sequences could be assigned to COG classifications in Roma (Additional file 5: Figure S4B). The cluster for "general function prediction only" represented the largest group, followed by "signal transduction mechanisms", "transcription", "replication, recombination and repair" and "carbohydrate transport and metabolism". Whereas no unigenes were assigned to "extracellular structure", "nuclear structure", "cell motility" and "intracellular trafficking, secretion, and vesicular transport”. 


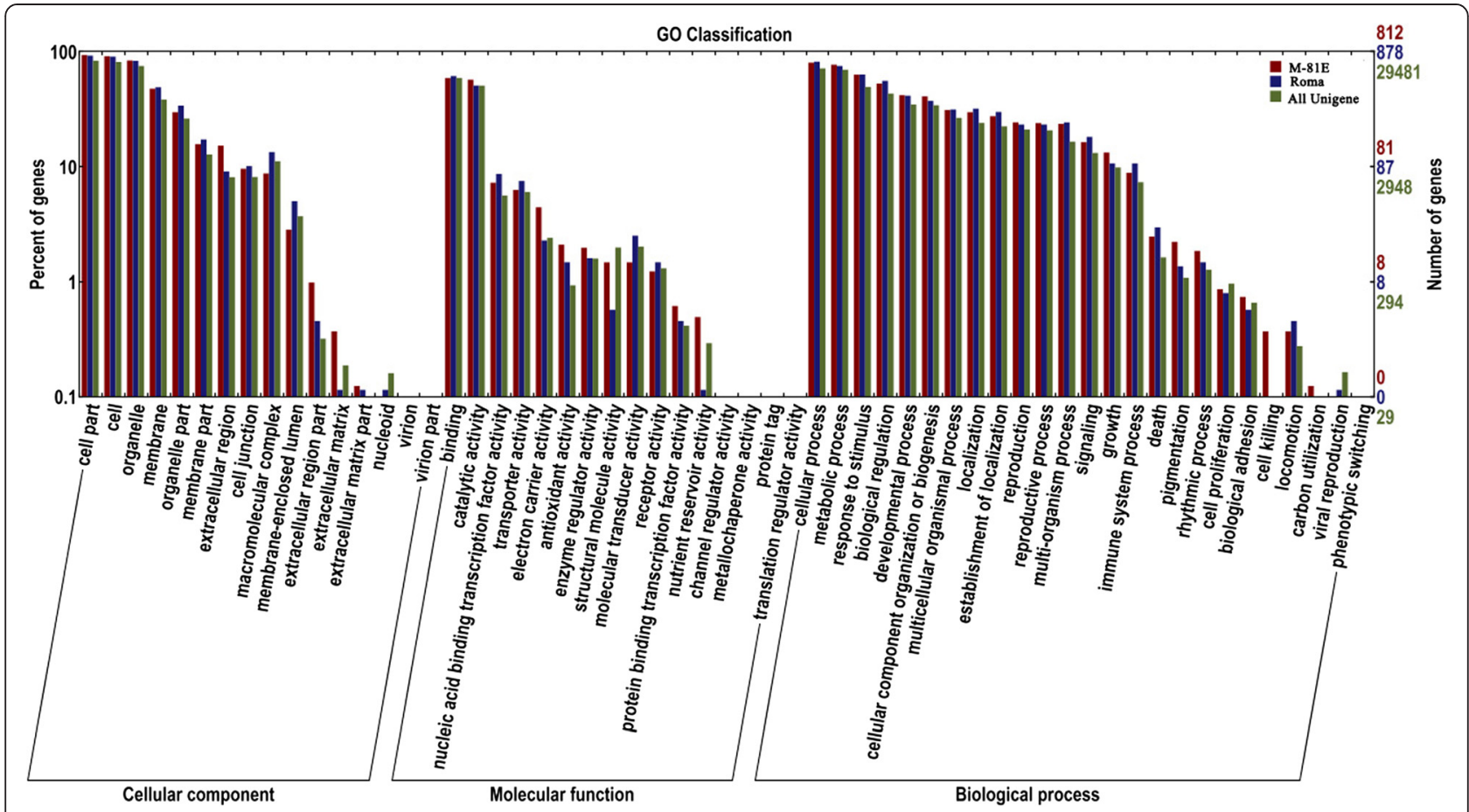

Fig. 7 Functional annotation of assembled sequences based on gene ontology (GO) categorization. Results are summarized for three main Go categories: Biological Process, Molecular Function, and Cellular Component

\section{Functional classification by KEGG}

Kyoto Encyclopedia of Genes and Genomes database (KEGG) [25] was used to identify potential biological pathways represented in the sweet sorghum transcriptome. There were 150 DEGs of M-81E and 174 DEGs of Roma assigned to 70 and 63 KEGG pathways, respectively. The majority of these DEGs mapped to "photosynthesis", "photosynthesis-antenna proteins", "carbon fixation in photosynthetic organisms" and "starch and sucrose metabolism" categories (Fig. 8, Table 1), which indicated that salt stress mainly affected photosynthesis and carbohydrate metabolism in leaves of sweet sorghum.

\section{Photosynthesis-antenna proteins}

In the first steps of photosynthesis, light energy is captured and converted into chemical energy. A large part of the light is absorbed by the outer light-harvesting complexes (LHCs), which contain most of the chlorophyll and carotenoid pigments and are peripherally associated with PSI and PSII [26, 27]. These LHC proteins are encoded by nuclear genes of the LHC multi-gene family coding for proteins that contain one to four trans-membrane helices and share a number of conserved chlorophyll- and xanthophyll-binding motifs [28]. In higher plants, 14 different types of LHC proteins (Lhca1-Lhca6 and Lhcb1-Lhcb8) are expressed [29]. Lhca-type proteins are organized into two heterodimeric domains (Lhca1/Lhca4 and Lhca2/Lhca3) as an external antenna with the PSI core. The reaction center of PSII is surrounded by Lhcb-type proteins. In the present study, 8 DEGs of M-81E and 14 DEGs of Roma were mapped to the antenna proteins, respectively. In comparison with the untreated control, the expression of DEGs encoding Lhca1 and Lhcb1-5 were down-regulated in both of the two genotypes under salt stress. However, the expression level of DEGs encoding Lcha2-4 and Lchb6 dropped under salt stress in Roma but did not change in $\mathrm{M}-81 \mathrm{E}$ (Additional file 6: Figure S5).

\section{Photosynthesis}

Photosynthesis is one of the most important metabolic processes in plants. Salt stress significantly impacts the photosynthetic rate $[30,31]$. The four protein components of the photosynthetic electron transport chain responsible for the electron transfer from water to $\mathrm{NADP}^{+}$are Photosystem II (PSII), Photosystem I (PSI), cytochrome (Cytb6f) complex, and ATP synthase. There were 11 and 20 DEGs of M-81E and Roma, respectively, that mapped to the photosynthesis pathway, which led to changes in the structure and function of the four protein components (Fig. 9, Table 1).

Photosystem II is a protein complex consisting of several different types of chlorophyll binding components. The function of these components is to organize chlorophylls for light harvesting and to harbor the electron transport intermediates as well as cofactors needed for 

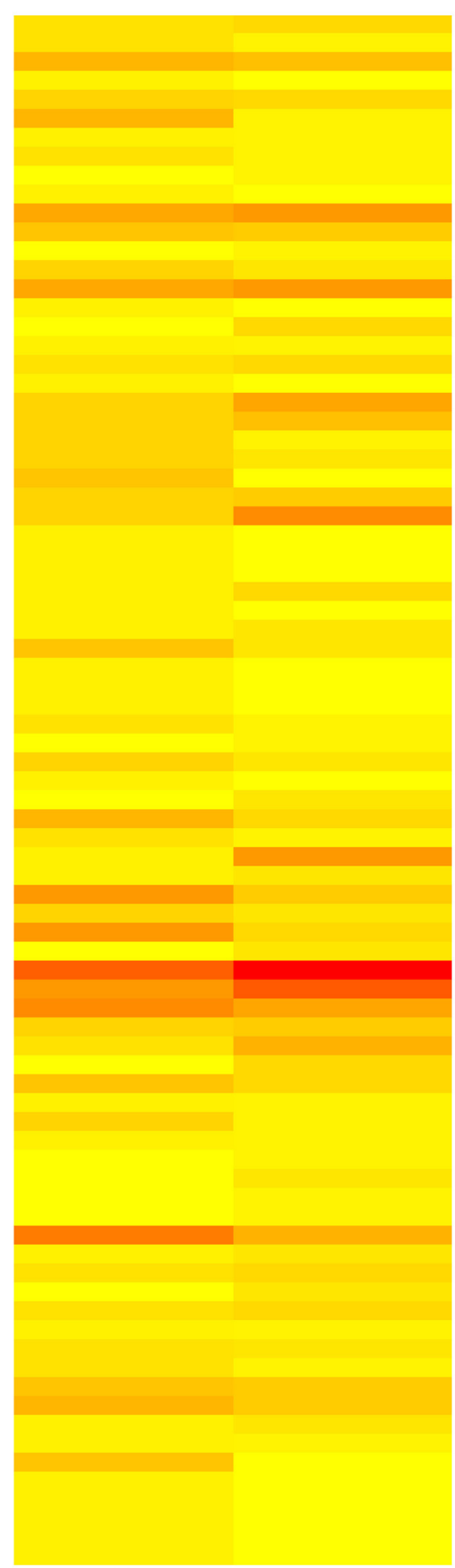

M-81E

Roma
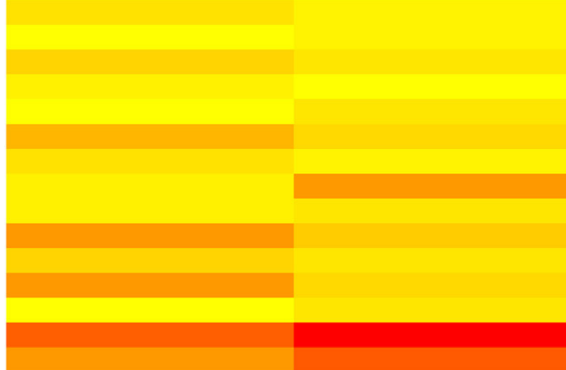

Alanine, aspartate and glutamate metabolism

alpha-Linolenic acid metabolism

Amino sugar and nucleotide sugar metabolism

Arachidonic acid metabolism

Arginine and proline metabolism

Ascorbate and aldarate metabolism

beta-Alanine metabolism

Biosynthesis of unsaturated fatty acids

Butanoate metabolism

Brassinosteroid biosynthesis

Carbon fixation in photosynthetic organisms

Carotenoid biosynthesis

Citrate cycle (TCA cycle)

Cyanoamino acid metabolism

Cysteine and methionine metabolism

Diterpenoid biosynthesis

Endocytosis

Ether lipid metabolism

Fatty acid metabolism

Flavonoid biosynthesis

Fructose and mannose metabolism

Galactose metabolism

Glutathione metabolism

Glycerolipid metabolism

Glycerophospholipid metabolism

Glycine, serine and threonine metabolism

Glycolysis / Gluconeogenesis

Glycosaminoglycan degradation

Glycosphingolipid biosynthesis - ganglio series

Glycosphingolipid biosynthesis - globo series

Glyoxylate and dicarboxylate metabolism

Histidine metabolism

Inositol phosphate metabolism

Isoquinoline alkaloid biosynthesis

Limonene and pinene degradation

Lysine biosynthesis

Lysine degradation

mRNA surveillance pathway

Nicotinate and nicotinamide metabolism

Nitrogen metabolism

Natural killer cell mediated cytotoxicity

One carbon pool by folate

Oxidative phosphorylation

Pentose and glucuronate interconversions

Pentose phosphate pathway

Peroxisome

Phenylalanine metabolism

Phenylalanine, tyrosine and tryptophan biosynthesis

Phenylpropanoid biosynthesis

Phosphatidylinositol signaling system

Photosynthesis

Photosynthesis - antenna proteins

Plant hormone signal transduction

Plant-pathogen interaction

Porphyrin and chlorophyll metabolism

Protein processing in endoplasmic reticulum

Purine metabolism

Pyrimidine metabolism

Pyruvate metabolism

Ribosome

Ribosome biogenesis in eukaryotes

RNA transport

Selenocompound metabolism

Spliceosome

Starch and sucrose metabolism

Steroid biosynthesis

Sulfur metabolism

Taurine and hypotaurine metabolism

Terpenoid backbone biosynthesis

Thiamine metabolism

Tropane, piperidine and pyridine alkaloid biosynthesis

Tryptophan metabolism

Tyrosine metabolism

Ubiquinone and other terpenoid-quinone biosynthesis

RNA polymerase

SNARE interactions in vesicular transport

Phagosome

Propanoate metabolism

Stilbenoid, diarylheptanoid and gingerol biosynthesis

Other glycan degradation

Valine, leucine and isoleucine degradation

Zeatin biosynthesis

Fig. 8 The heat map display of DEGs assigned to different KEGG pathways. The numbers in the scale bar show the percentage of the number of DEGs assigned to a certain KEGG pathway in which assigned to all KEGG pathways. Red indicates that more genes are enriched in this pathway 
Table 1 DEGs mapped to KEGG pathways related with sugar content

\begin{tabular}{|c|c|c|c|c|c|c|c|}
\hline \multirow[t]{2}{*}{ Gene ID } & \multirow[t]{2}{*}{ Annotation } & \multicolumn{3}{|l|}{$\mathrm{M}-81 \mathrm{E}$} & \multicolumn{3}{|l|}{ Roma } \\
\hline & & FDR & $\log 2 \mathrm{FC}$ & regulated & FDR & $\log 2 \mathrm{FC}$ & regulated \\
\hline \multicolumn{8}{|c|}{ A: Photosynthesis - antenna proteins } \\
\hline Sb01g015400 & Chlorophyll a-b binding protein & $1.63 \mathrm{E}-05$ & -1.61 & down & 2.66E-07 & -2.15 & down \\
\hline Sb02g032040 & Chlorophyll a-b binding protein 1 & - & - & - & $5.56 \mathrm{E}-16$ & -2.47 & down \\
\hline Sb02g036260 & Chlorophyll a-b binding protein CP29.1 & $1.56 \mathrm{E}-14$ & -1.5 & down & 0 & -1.38 & down \\
\hline Sb02g036380 & Chlorophyll a-b binding protein & 4.11E-14 & -2.37 & down & $1.39 \mathrm{E}-06$ & -1.62 & down \\
\hline Sb02g037410 & Chlorophyll a-b binding protein 7 & - & - & - & 0 & -1.36 & down \\
\hline Sb03g027030 & Chlorophyll a-b binding protein 2 & - & - & - & $1.44 \mathrm{E}-24$ & -3.45 & down \\
\hline Sb03g027040 & Chlorophyll a-b binding protein 2 & $6.22 \mathrm{E}-35$ & -2.41 & down & 4.37E-17 & -2.78 & down \\
\hline Sb04g004770 & Chlorophyll a-b binding protein 1B-21 & $2.35 \mathrm{E}-12$ & -1.48 & down & 0 & -1.54 & down \\
\hline Sb05g007070 & Chlorophyll a-b binding protein CP26 & $5.84 \mathrm{E}-16$ & -2.01 & down & $1.95 \mathrm{E}-05$ & -1.68 & down \\
\hline Sb06g032690 & Chlorophyll a-b binding protein CP24 10B & - & - & - & $6.29 \mathrm{E}-09$ & -1.62 & down \\
\hline Sb07g021260 & Chlorophyll $a-b$ binding protein 4 & - & - & - & $2.55 \mathrm{E}-05$ & -1.74 & down \\
\hline Sb09g028720 & Chlorophyll a-b binding protein M9 & $3.80 \mathrm{E}-05$ & -1.42 & down & 0 & -1.36 & down \\
\hline Sb10g023930 & Chlorophyll a-b binding protein 8 & - & - & - & 0 & -1.49 & down \\
\hline Sb01g015400 & Chlorophyll a-b binding protein & $1.63 \mathrm{E}-05$ & -1.61 & down & $2.66 \mathrm{E}-07$ & -2.15 & down \\
\hline \multicolumn{8}{|c|}{ B: Photosynthesis } \\
\hline Sb01g004330 & Photosystem I reaction center subunit || & - & - & - & 1.05E-05 & -1.62 & down \\
\hline Sb01g006370 & Photosystem I reaction center subunit III & - & - & - & 0.01 & -1.1 & down \\
\hline Sb01g012850 & Ferredoxin & - & - & - & 0 & -1.11 & down \\
\hline Sb01g036240 & Photosystem II repair protein PSB27-H1 & 7.37E-12 & -1.37 & down & $1.05 \mathrm{E}-05$ & -1.35 & down \\
\hline Sb02g002830 & Photosystem II 10 kDa polypeptide, chloroplastic (Precursor) & $5.40 \mathrm{E}-09$ & 2.16 & up & - & - & - \\
\hline Sb02g002960 & Photosystem I reaction center subunit psaK & $6.29 \mathrm{E}-14$ & -1.5 & down & $1.25 \mathrm{E}-06$ & -1.83 & down \\
\hline Sb02g010190 & Photosystem I reaction center subunit IV & - & - & - & 0 & -1.22 & down \\
\hline Sb02g035610 & Oxygen-evolving enhancer protein 3-1 & $9.12 \mathrm{E}-09$ & -1.15 & down & 0 & -1.12 & down \\
\hline Sb02g027900 & Photosystem I reaction center subunit $\mathrm{V}$ & - & - & - & 0 & -1.7 & down \\
\hline Sb02g034570 & ATP synthase subunit gamma & - & - & - & 0.01 & -1 & down \\
\hline Sb03g004560 & Photosystem I reaction center subunit XI & - & - & - & 0 & -1.41 & down \\
\hline Sb03g036090 & Photosystem II reaction center W protein & - & - & - & 0 & -1.39 & down \\
\hline Sb04g023940 & PsbQ-like protein 1 & - & - & - & 0.01 & -1.07 & down \\
\hline Sb04g027810 & ATP synthase delta chain & $1.22 \mathrm{E}-08$ & -1.15 & down & 0 & -1.07 & down \\
\hline Sb06g016090 & hypothetical protein SORBIDRAFT_06g016090 & $2.50 \mathrm{E}-07$ & -1.05 & down & 1.88E-09 & -2.04 & down \\
\hline Sb07g000600 & Ferredoxin-1 & $1.83 \mathrm{E}-15$ & -1.55 & down & 0 & -2.02 & down \\
\hline Sb07g000610 & Ferredoxin-1 & - & - & - & $3.78 \mathrm{E}-05$ & -1.2 & down \\
\hline Sb07g000620 & Ferredoxin-1 & 0 & -1.54 & down & 0.01 & -1.22 & down \\
\hline Sb09g021810 & Ferredoxin-6 & 0 & 1.69 & up & - & - & - \\
\hline Sb08g005300 & Photosystem I reaction center subunit $\mathrm{N}$ & - & - & - & $1.74 \mathrm{E}-05$ & -1.49 & down \\
\hline Sb09g028260 & Photosystem I reaction center subunit VI & $6.72 \mathrm{E}-07$ & -1.02 & down & $6.56 \mathrm{E}-06$ & -1.66 & down \\
\hline Sb10g000230 & Plastocyanin & $5.08 \mathrm{E}-09$ & -1.25 & down & 0 & -1.32 & down \\
\hline \multicolumn{8}{|c|}{ C:Carbon fixation in photosynthetic organisms } \\
\hline Sb02g004280 & Probable ribose-5-phosphate isomerase & - & - & - & 5.79E-05 & -1.2 & down \\
\hline Sb03g043140 & Fructose-bisphosphate aldolase & - & - & - & $5.10 \mathrm{E}-05$ & 1.27 & up \\
\hline Sb05g003480 & Ribulose bisphosphate carboxylase small chain & $2.33 \mathrm{E}-09$ & -1.49 & down & 0 & -1.36 & down \\
\hline Sb05g004590 & Fructose-bisphosphate aldolase & - & - & - & $6.28 \mathrm{E}-08$ & -1.73 & down \\
\hline
\end{tabular}


Table 1 DEGs mapped to KEGG pathways related with sugar content (Continued)

\begin{tabular}{|c|c|c|c|c|c|c|c|}
\hline Sb06g004280 & Transketolase & $1.02 \mathrm{E}-12$ & Inf & up & 0 & 2.64 & up \\
\hline Sb10g002220 & Transketolase & - & - & - & 0 & -1.05 & down \\
\hline Sb10g026710 & Phosphoglycerate kinase & - & - & - & 0 & 1.98 & up \\
\hline Sb01g023750 & Alanine aminotransferase 2 & $1.00 \mathrm{E}-11$ & 1.37 & up & - & - & - \\
\hline Sb03g034280 & NADP-dependent malic enzyme & 4.64E-05 & Inf & up & - & - & - \\
\hline Sb06g018880 & Glyceraldehyde-3-phosphate dehydrogenase A, & 0 & -1.08 & down & - & - & - \\
\hline \multicolumn{8}{|c|}{ D:starch and sucrose metabolism } \\
\hline Sb01g035890 & Sucrose synthase 4 & $5.12 \mathrm{E}-05$ & 1.92 & up & - & - & - \\
\hline Sb02g020410 & Glucose-1-phosphate adenylyltransferase small subunit & 2.04E-05 & 2.02 & up & - & - & - \\
\hline Sb03g012830 & Pectinesterase 1 (Precursor) & $3.45 \mathrm{E}-09$ & $-\operatorname{lnf}$ & down & - & - & - \\
\hline Sb04g021540 & 1,4-alpha-glucan-branching enzyme 2 & 0 & 1.32 & up & - & - & - \\
\hline Sb06g022410 & Beta-glucosidase 16 (Precursor) & $1.84 \mathrm{E}-08$ & -1.65 & down & - & - & - \\
\hline Sb06g022450 & Probable inactive beta-glucosidase 14 (Precursor) & 0.01 & -2.73 & down & - & - & - \\
\hline Sb06g023760 & Beta-fructofuranosidase 1 (Precursor) & $9.66 \mathrm{E}-06$ & -1.56 & down & $5.28 \mathrm{E}-06$ & 1.44 & up \\
\hline Sb09g005840 & Hexokinase-7 & $1.69 \mathrm{E}-07$ & -1.47 & down & 0 & 1.49 & up \\
\hline Sb09g025790 & Alpha,alpha-trehalose-phosphate synthase [UDP-forming] & $1.03 \mathrm{E}-06$ & -1.36 & down & - & - & - \\
\hline Sb01g007580 & UDP-glucose 6-dehydrogenase 5 & - & - & - & 0 & 1.23 & up \\
\hline Sb08g019260 & Probable galacturonosyltransferase 13 & - & - & - & 0 & 1.07 & up \\
\hline Sb09g022050 & Probable beta-D-xylosidase 2 (Precursor) & - & - & - & 4.87E-11 & 2.13 & up \\
\hline Sb09g029610 & Glucose-1-phosphate adenylyltransferase large subunit & - & - & - & $1.16 \mathrm{E}-07$ & 1.58 & up \\
\hline
\end{tabular}

DEGs mapped to photosynthesis-antenna proteins, photosynthesis, carbon fixation in photosynthetic organisms and starch and sucrose metabolism pathway. "Inf" means Infinite, "-" means the expression of the gene was not changed under salt stress

the oxidation of water [32]. After treated with $\mathrm{NaCl}$, DEGs encoding PsbQ, which is necessary for regulation of activity and assembly [33, 34] of PSII in both M-81E and Roma, were down-regulated. PsbR has been proved to be an important link in the PSII core complex to permit stable assembly of the oxygen-evolving complex proteins PsbP and PsbQ [35]. DEGs encoding PsbR were up-regulated in M-81E after treated with $150 \mathrm{mM} \mathrm{NaCl}$ for $48 \mathrm{~h}$. DEGs encoding PsbW, which stabilize the supramolecular organization of photosystem II, were down-regulated only in Roma. These results suggested that salt stress reduced the binding stability of several subunits of PSII. However, we predict that M-81E may protect important connective structures from being destroyed by increasing expression of specific genes.

Photosystem I (PSI) from higher plants is a supramolecular complex which catalyzes the light-driven electron transfer from plastocyanin to ferredoxin and is composed of a chlorophyll binding core complex and a chlorophyll $\mathrm{a} / \mathrm{b}$ binding peripheral antenna called LHCI [36]. After treated with $\mathrm{NaCl}$ for $48 \mathrm{~h}$, the expression of DEGs encoding PsaK, PsaH and PsaO decreased in both genotypes. All of these three subunits are involved in the interaction between the light-harvesting complex (LHC) and Photosystem I [37-39], suggesting that salt stress weakened the connection between LHCs and PSI and reduced the conversion of light energy to chemical energy. PsaD, PsaE, PsaF, PsaG, PsaL and PsaN encoding genes were down-regulated only in Roma. Among them, four subunits (PsaD, PsaE, PsaF, PsaN) are considered to be important for the interaction with ferredoxin or plastocyanin $[40,41]$, indicating that the electron transport mechanism was inhibited by salt stress in Roma. These observations agreed fairly well with the down-regulation of petE and petF in Roma after treated with salt. Moreover, expression of Sb04g027810, a gene encoding the ATP synthase delta chain, decreased in both genotypes when treated with $150 \mathrm{mM} \mathrm{NaCl}$, while the gene encoding the ATP synthase gamma chain was only down-regulated in Roma.

\section{Carbon fixation in photosynthetic organisms}

There were 6 and 8 DEGs of M-81E and Roma, respectively, mapped to the carbon fixation in photosynthetic organisms pathway. Ribulose-bisphosphate carboxylase (rubisco, EC: 4.1.1.39), phosphoenolpyruvate carboxylase (PEPC, EC:4.1.1.31) and pyruvate orthophosphate dikinase (PPDK, EC:2.7.9.1) are considered as key enzymes in the process of carbon fixation. Rubisco catalyzes the incorporation of $\mathrm{CO}_{2}$ into ribulose 1,5-bisphosphate [42]. Under salt stress for $48 \mathrm{~h}$, the expression of DEGs encoding rubisco decreased while the PPDK and PEPC encoding genes remained unchanged in both genotypes based on our RNA-seq data. Surprisingly, the expression 


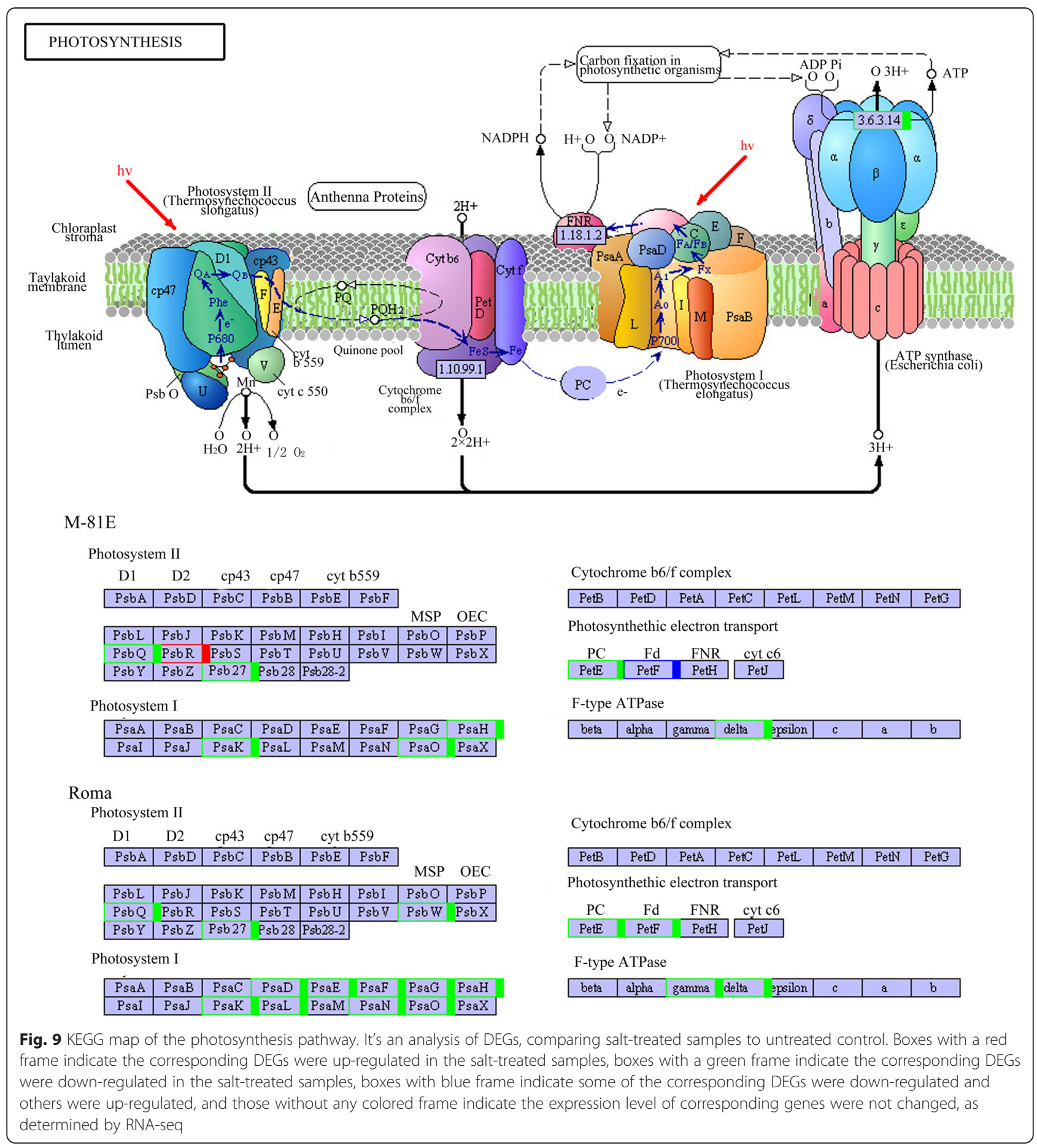

of DEGs encoding transketolase (EC:2.2.1.1) and $\mathrm{NADP}^{+}$-malate dehydrogenase (NADP-ME, 1.1.1.40) in $\mathrm{M}-81 \mathrm{E}$ were extremely enhanced by salt stress (Additional file 7: Figure S6).

\section{Starch and sucrose metabolism}

Sucrose phosphate synthetase (SPS, EC:3.1.3.24), sucrose synthetase (SS, EC:2.4.1.13) and invertase (INV,
EC:3.2.1.26) are considered to be key enzymes in sucrose metabolism. SS is known to play a role in sucrose synthesis using uridine diphosphate (UDP)-glucose and fructose as substrates and its activity is high in source tissues such as leaves [43]. After a $48 \mathrm{~h}$ treatment with $\mathrm{NaCl}$, the expression of DEGs encoding SS were enhanced in M-81E but unchanged in Roma. INV plays the most important role in the decomposition of 
sucrose. In the present study, the expression of DEGs encoding INV decreased in M-81E but increased in Roma during salt stress (Additional file 8: Figure S7).

\section{Verification of RNA-seq data}

We performed quantitative real-time PCR on 14 randomly selected DEGs to validate the RNA-seq gene expression analysis. As shown in Fig. 10, a high correlation $\left(\mathrm{R}^{2}=0.93\right)$ between RNA-seq and qRT-PCR was observed. Also, three genes (Sb03g034280, Sb06g023760 and Sb01g035890) which may play important roles in improving sugar content in sweet sorghum were confirmed by qPCR, too. As shown in Fig. 11, a high correlation $\left(R^{2}=0.92\right)$ was observed, confirming the reliability of the RNA-seq data.

\section{Discussion}

Sweet sorghum has been considered to be a plant with relatively high salt tolerance [9, 12, 44]. In our work, however, $\mathrm{NaCl}$ caused a dramatic decrease in leaf length, leaf number, FW and DW in Roma, while growth parameters in M-81E were less affected (Fig. 1, Additional file 1: Figure S1 and Additional file 2: Figure S2). These results were consistent with previous studies that M-81E was observed to be relatively salt-tolerant but Roma was salt-sensitive.

Generally, the effects of salt stress include ion toxicity and osmotic stress. Ion toxicity is mainly caused by $\mathrm{Na}^{+}$. Increases in $\mathrm{Na}^{+}$concentration during salt stress have been well established $[45,46]$. Since sweet sorghum has the ability to exclude toxic ions and store the absorbed toxic ions in the root cell vacuoles while maintaining higher levels of $\mathrm{K}^{+}$uptake [9], the accumulation of $\mathrm{Na}^{+}$ in leaves can be limited. In the present study, the accumulation of $\mathrm{Na}^{+}$in leaves was not significantly affected in both our tested genotypes under $50 \mathrm{mM} \mathrm{NaCl}$ stress condition for 7 days. At $150 \mathrm{mM} \mathrm{NaCl}$, however, $\mathrm{Na}^{+}$ concentration was significantly increased in both genotypes, particularly in Roma by a factor of six (Additional file 3: Figure S3). High concentration of $\mathrm{Na}^{+}$impairs the ability of plants to accumulate essential nutrients [47], such as $\mathrm{K}^{+}$, which are required to maintain the stability and functioning of cell membranes and associated enzymes. Maintenance of adequate $\mathrm{K}^{+}$levels in plant tissues under salt stress has been reported to be dependent on selective cellular $\mathrm{K}^{+}$and $\mathrm{Na}^{+}$distribution [48]. $\mathrm{K}^{+}$ content decreased with raised $\mathrm{NaCl}$ concentration and as a result, the $\mathrm{K}^{+} / \mathrm{Na}^{+}$ratios decreased. These results indicated that sweet sorghum limited accumulation of $\mathrm{Na}^{+}$under $50 \mathrm{mM} \mathrm{NaCl}$ treatment, while at a $\mathrm{NaCl}$ concentration increased of $150 \mathrm{mM}$, Roma lost the ability to control the absorption of $\mathrm{Na}^{+}$.

In order to compare the salt response of sugar content in leaves of M-81E and Roma at the transcriptome level, RNA-seq was performed using leaves treated with 0 and $150 \mathrm{mM} \mathrm{NaCl}$ for $48 \mathrm{~h}$. In response to salt stress, a larger number of DEGs were observed in Roma compared to M-81E (Fig. 6). In a previous study, the results showed that the salt tolerant plants had a smaller number of salt-regulated genes in salt cress [49]. However, another study indicated that a salt-sensitive tomato PI365967 showed a relatively smaller amount of saltregulated genes than Moneymaker which is more tolerant to salt [22]. These results suggested that the number of salt-regulated genes may not be directly linked to the degree of salt tolerance.

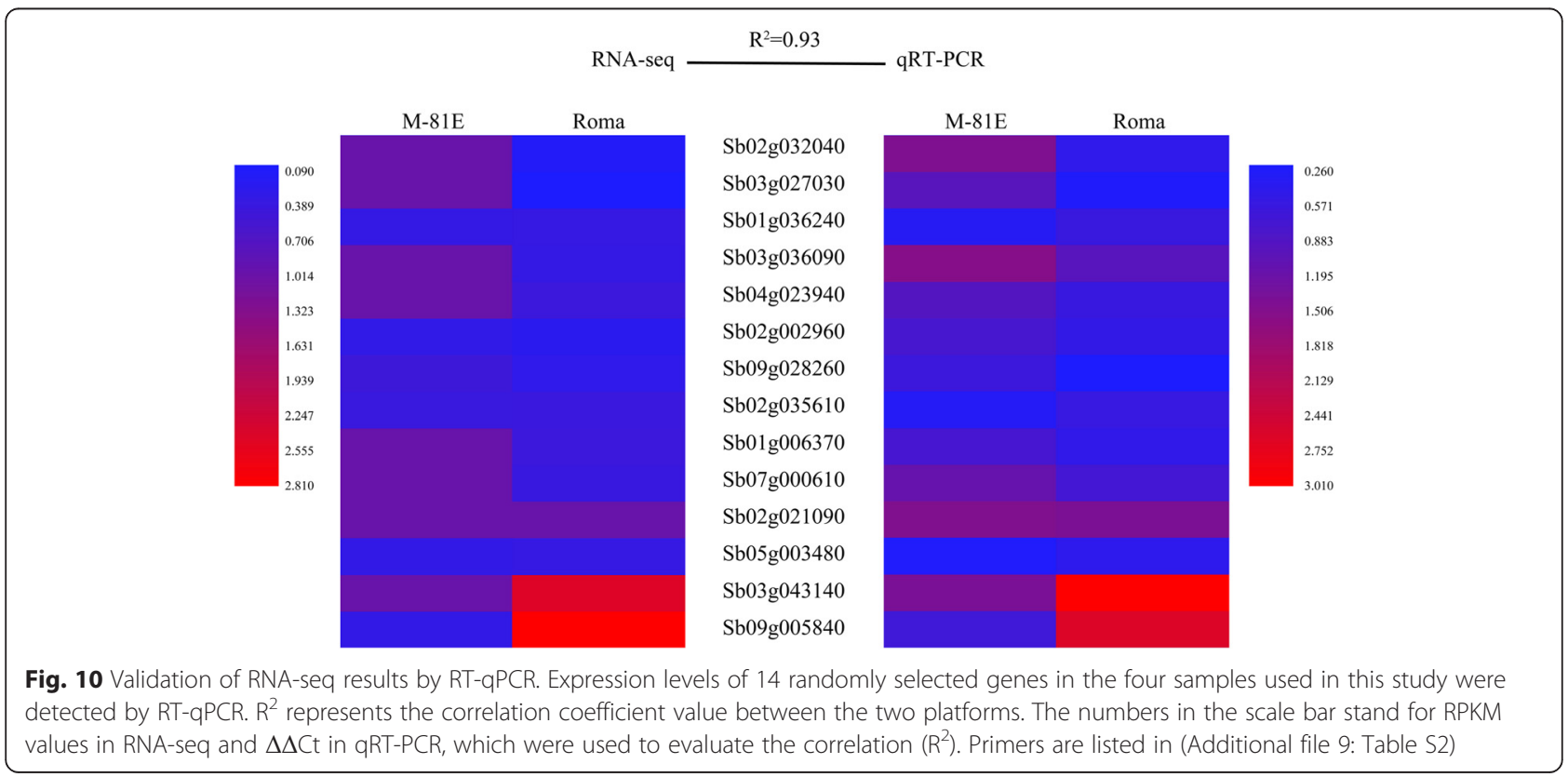




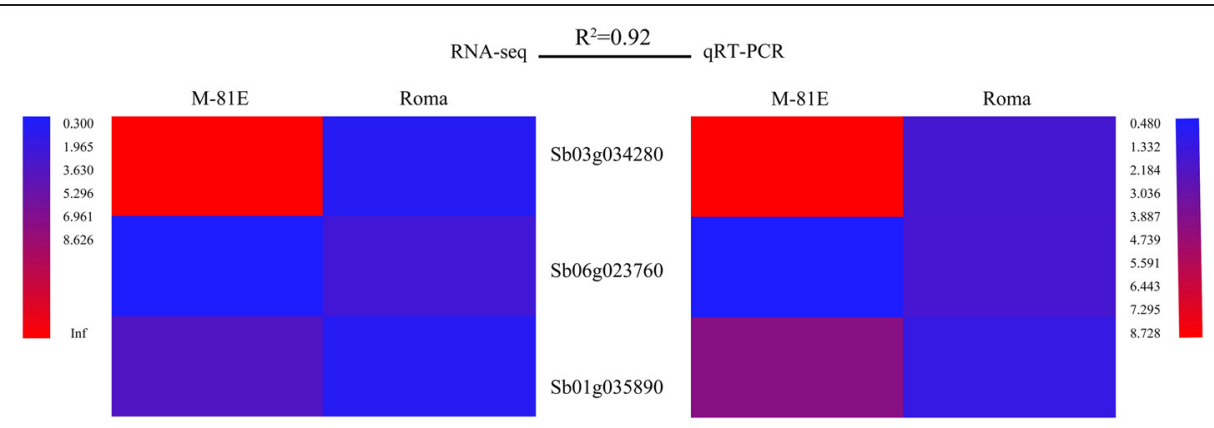

Fig. 11 Validation of RNA-seq results by RT-qPCR. Expression levels of 3 genes involved in sucrose synthesis and metabolism pathways were detected by RT-qPCR. R $^{2}$ represents the correlation coefficient value between the two platforms. The numbers in the scale bar stand for RPKM values in RNA-seq and $\Delta \Delta C t$ in qRT-PCR, which were used to evaluate the correlation ( ${ }^{2}$ ). Primers are listed in (Additional file 9: Table S2)

Pathway analysis is an effective way to characterize "gene networks" under salt stress. We observed that genes related with photosynthesis and light-harvesting proteins were mainly repressed by salinity. There were 20 DEGs mapped to the photosynthesis pathway in Roma and all of them were down-regulated under salt stress. Most of these genes were related to the structure of the photosystem complex, the electron transport chain and the connection between photosystem complexes and light-harvesting proteins (Table 1). Only 11 DEGs in M-81E mapped to the photosynthesis pathway with 9 down-regulated genes and 2 up-regulated genes, which were related to the stable assembly of the oxygenevolving complex and ATP synthase. These results suggest that salt stress could damages the structure of the photosystem and reduces the efficiency of electron transportation, which may result in decreased ATP and NADPH levels in plants under salt stress. This damage is particularly severe in salt-sensitive species, while salttolerant species can protect important connective structures from being destroyed by keeping low concentration of $\mathrm{Na}^{+}$in leaves and increasing the expression of particular genes. As a result, there was no significant change in Fv/Fm of M-81E, while Fv/Fm of Roma decreased gradually with the increasing $\mathrm{NaCl}$ treatments. Furthermore, the decrease in ФPSII was more significant in Roma (Fig. 2). There were 7 and 13 DEGs mapped to the photosynthesis-antenna proteins pathway in $\mathrm{M}-81 \mathrm{E}$ and Roma, respectively. All of these genes were downregulated under salt stress (Table 1), suggesting that the ability to capture and convert light energy of both genotypes was affected by salt stress. As light-harvesting complexes contain most of the chlorophyll and carotenoid pigments, the down-regulation of those genes resulted in decreases in chlorophyll content (Fig. 3), particularly in the salt-sensitive genotype Roma.

Rubisco, PEPC and PPDK are well known as the key enzymes in the dark reaction of photosynthesis. Rubisco plays an important role in $\mathrm{CO}_{2}$ assimilation. Salt stress led to a reduced expression of Rubisco encoding gene in both M-81E and Roma, suggesting that salt stress reduced the efficiency of $\mathrm{CO}_{2}$ assimilation in sweet sorghum as has been shown in previous studies [50-53]. To our surprise, the expression of the gene encoding NADP-ME was extremely enhanced by salt stress in M81E. NADP-ME is important for the carbon fixation pathway because it catalyzes the reversible oxidative decarboxylation of L-malate to produce $\mathrm{CO}_{2}$, pyruvate and NADPH $[54,55]$. It has been shown that the expression of the gene encoding NADP-ME can be activated by salt stress [56, 57]. NADP-MEs are not only an important for photosynthesis, but are also involved in plant defense reactions and environmental stress responses [58]. In our study, the gene encoding NADP-ME was up-regulated by salt stress in $\mathrm{M}-81 \mathrm{E}$ which could increase the content of $\mathrm{CO}_{2}$, pyruvate and $\mathrm{NADPH}$. The increasing $\mathrm{CO}_{2}$ and pyruvate levels enhanced the efficiency of the dark reaction of photosynthesis. In our research, photosynthetic rate of M-81E was not significantly affected by salt stress (Fig. 4), which might be related to the up-regulation of $N A D P-M E$. After treated with $150 \mathrm{mM} \mathrm{NaCl}$, in Roma, photosynthetic rate and stomatal conductance decreased, while the intracellular $\mathrm{CO}_{2}$ concentration increased (Fig. 4). This showed that the decrease of photosynthetic rate was attributed to the non-stomatal factors, which might be related to the down expression of Rubisco. Recent studies showed that NADP-ME plays a role in enhancing tolerance of plants to salt stress $[57,59]$. Salt stress can produce superabundant reactive oxygen species (ROS) causing oxidative stress in plants [60-62]. Additionally, NADPH provides the reducing power required for ROS metabolism [63]. Møller and Rasmusson (1998) reported that NADPH can be used by the NADPH-specific glutathione reductase (GR) to catalyze the reduction of glutathione for scavenging ROS by an ascorbate coupled system [64]. In our study, the upregulation of NADP-ME encoding gene may play a role in the stress response and in the dark reaction of 
photosynthesis in salt-tolerant species of sweet sorghum. The increase of NADP-ME content enhanced the recycling of $\mathrm{CO}_{2}$ in the $\mathrm{C} 4$ pathway. Furthermore, it may reduce the damage caused by ROS.

After treated with $\mathrm{NaCl}$ for 7 days, there was a significant difference in sugar content between M-81E and Roma. The sugar content increased $99.7 \%$ in M-81E and decreased $30.5 \%$ in Roma under $150 \mathrm{mM} \mathrm{NaCl}$, suggesting that salt stress strongly induced the accumulation of sugar in salt-tolerant genotype of sweet sorghum (Fig. 5). Sucrose is the main source of carbon and of energy the sink tissues of sweet sorghum [8]. The cytoplasm of leaves is the site for sucrose synthesis. After synthesized, sucrose will be loaded into phloem and transported to sink tissues (stem and/or panicle). Various enzymes involved in sugar metabolism are required to ensure that sucrose is synthesized efficiently and the flow of sucrose is unidirectional (from source to the sink) [65]. SS is known to play a role in sucrose synthesis and its activity is high in source tissues such as leaves [43]. SPS can synthesize sucrose phosphate, which is converted to sucrose by sucrose phosphate phosphatase (SPP) in source tissues and then loaded into phloem. INV plays the most important role in the decomposition of sucrose. The vacuolar invertase activity is high in rapidly growing tissues [66]. Sucrose transporters (SUTs) are important exporters of photosynthetically-produced sugar, principally sucrose, from leaves to sink tissues [67]. It has been reported that the expression of sucrosemetabolizing enzymes play an important role in the accumulation of sucrose. In our study, the SS gene was up-regulated only in M-81E by salt treatment. However, the gene encoding INV was found to be up-regulated in Roma but down-regulated in M-81E (Additional file 8: Figure S7, Table 1). These findings suggest that salttolerant species of sweet sorghum accumulate more sucrose by enhancing the synthesis and reducing the decomposition of sucrose under salt stress. While, saltsensitive species enhance decomposition of sucrose under salt stress in order to meet the energy demand of growth. Furthermore, genes encoding SUTs showed no differential expression after treated with $150 \mathrm{mM} \mathrm{NaCl}$ in either genotype, suggesting that the transportation of sucrose from leaves to stem is not affected by salt stress treatment for $48 \mathrm{~h}$ at seedling stages.

\section{Conclusions}

In conclusion, we report here that the salt-tolerant genotype M-81E can increase sugar content under salt stress. This may be caused by the changes in expression level of genes related to important structures of photosystems and LHCs and genes encoding key enzymes of sucrose synthetase and sucrose decomposition under salt stress (Fig. 12). This RNA-seq dataset is an important resource for future studies aimed at improving sugar content of sweet sorghum under salt stress. Further genetic and biochemical analysis will be critical to understanding the detailed gene function and the relationship between salt tolerance and sugar content in sweet sorghum.

\section{Methods}

\section{Plant materials and growth conditions}

Seeds of two sweet sorghum genotypes M-81E and Roma were used as the experimental materials in this study. M$81 \mathrm{E}$ is considered to be tolerant to salt stress [9], while Roma is sensitive to salt stress. After being washed with tap water for $8 \mathrm{~h}$, plump seeds were selected and sowed in plastic pots filled with river sand and irrigated with tap water. After germination, they were irrigated with $1 / 2$ Hoagland solution in controlled growth chambers. The seedlings were cultured at $28 \pm 3 / 23 \pm 3{ }^{\circ} \mathrm{C}$ (day/night) at a light intensity of $600 \mu \mathrm{mol} \mathrm{m} \mathrm{m}^{-2} \mathrm{~s}^{-1}$ (15 h photoperiod) and $70 \%$ relative humidity. Salt treatment was performed at the four-leaf stage. The treated plants were irrigated with nutrient solution supplemented with 0, 50 and $150 \mathrm{mM} \mathrm{NaCl}$. The $\mathrm{NaCl}$ concentrations were increased stepwise towards the final concentrations by $50 \mathrm{mM}$ each day.

\section{Measurement of fresh weight and dry weight}

After exposure to salt treatments for 7 days, 15 plants from each treatment ( 5 per replicate) were sampled to determine leaf length and leaf number. Leaves were then separated and their FW were directly determined. For DW determination, the leaves were weighed after being dried at $150{ }^{\circ} \mathrm{C}$ for $15 \mathrm{~min}$ and $70{ }^{\circ} \mathrm{C}$ for $72 \mathrm{~h}$. Water content $(\mathrm{WC})$ was defined as follows: WC $(\%)=[(\mathrm{FW}-\mathrm{DW}) /$ FW $\times 100$.

\section{Analysis of inorganic ions}

For $\mathrm{Na}^{+}$and $\mathrm{K}^{+}$analysis, samples of dried leaves were ashed in a furnace for $6 \mathrm{~h}$ at $500{ }^{\circ} \mathrm{C}$. The ash was dissolved in $20 \%$ nitric acid, diluted in distilled water and filtered through a sheet of filter paper. $\mathrm{Na}^{+}$and $\mathrm{K}^{+}$ contents were determined by flame emission photometry (Flame Photometer 410,UK). Inorganic ion contents were expressed in $\mathrm{mg} \mathrm{g}^{-1} \mathrm{DW}$.

\section{Measurements of chlorophyll fluorescence}

After exposure to salt treatments for 7 days, chlorophyll fluorescence was measured. For each treatment, the parameters of Chl fluorescence were measured independently on five plants. Measurements were taken on the mature leaves of each of the chosen plants. Chl fluorescence was measured using a portable fluorometer (FMS2, Hansatech, King's Lynn, UK) following the protocol described by Kooten and Snel [68]. Leaves had been pre-darkened for at least $1 \mathrm{~h}$ in order to determine 


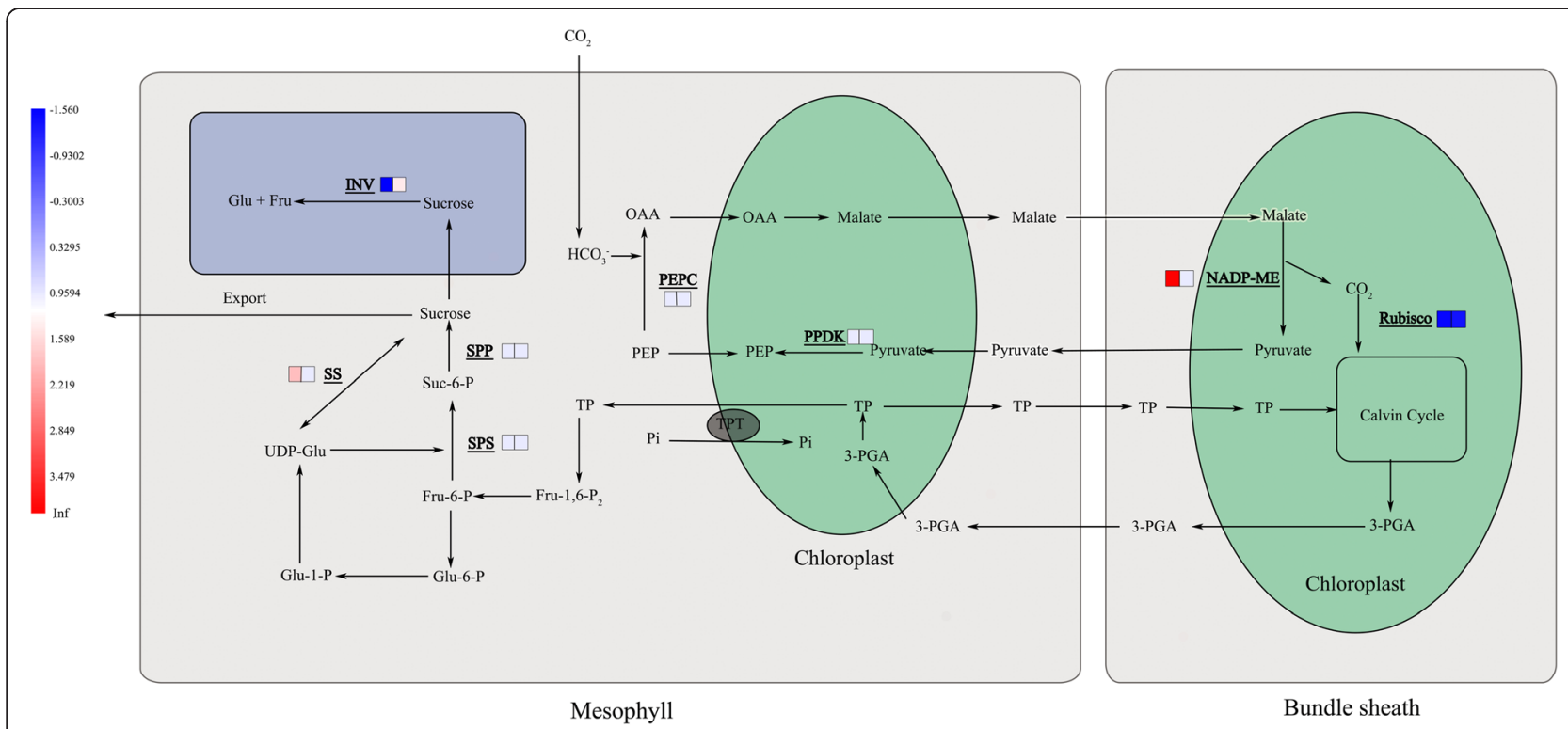

Fig. 12 visualization of DEGs involved in pathways related with the accumulation of sugar. A square block represents a gene assigned to our RNA-seq data. Blue represents the gene was down-regulated in salt-treated samples compared to the control samples. Red represents the gene was up-regulated. For each gene, the square block on the left stand for M-81E and the right one stand for Roma

the minimal and the maximal fluorescence. Minimal fluorescence (Fo) with all PSII reaction centers open was determined by modulated light which was low enough not to induce any significant variable fluorescence (Fv). Maximal fluorescence (Fm) [43] with all reaction centers closed was determined by $0.8 \mathrm{~s}$ saturating light of $8000 \mu \mathrm{mol} \mathrm{m} \mathrm{m}^{-2} \mathrm{~s}^{-1}$ on a dark-adapted leaf. Then the leaf was illuminated by an actinic light of $500 \mu \mathrm{mol} \mathrm{m} \mathrm{m}^{-2} \mathrm{~s}^{-1}$. Steady-state fluorescence (Fs) was recorded when the leaf reached steady-state photosynthesis. A second $0.8 \mathrm{~s}$ saturating light of $8000 \mu \mathrm{mol} \mathrm{m} \mathrm{m}^{-2} \mathrm{~s}^{-1}$ was given to determine maximal fluorescence in the light-adapted state (Fm'). Maximal photochemical efficiency $(\mathrm{Fv} / \mathrm{Fm})$ of PSII was expressed as: $\mathrm{Fv} / \mathrm{Fm}=(\mathrm{Fm}-\mathrm{Fo}) / \mathrm{Fm}$. Quantum yield of PSII electron transport was: $\Phi$ PSII $=\left(\mathrm{Fm}^{\prime}-\mathrm{Fs}\right) / \mathrm{Fm}^{\prime}$.

\section{Measurement of chlorophyll content}

Leaves $(0.2 \mathrm{~g}$ FW) were washed in distilled water and extracted in $5 \mathrm{ml} 80 \%$ acetone and $5 \mathrm{ml}$ dimethyl sulfoxide at $65{ }^{\circ} \mathrm{C}$ in darkness for $24 \mathrm{~h}$. The extract was adjusted to a total volume of $25 \mathrm{ml}$ with $80 \%$ acetone. The absorbance of the extract was determined at 663 and $645 \mathrm{~nm}$ using a spectrophotometer of BECKMAN DU2600. The amount of total chlorophyll was calculated using the Arnon [69] formulae as follows: Chla $(\mathrm{mg} / \mathrm{g})=\left(12.7 \mathrm{~A}_{663}-2.69 \mathrm{~A}_{645}\right) \times \mathrm{V} / 1000 \mathrm{~W}$; $\mathrm{Chlb}(\mathrm{mg} / \mathrm{g})=\left(22.9 \mathrm{~A}_{645}-4.68 \mathrm{~A}_{663}\right) \times \mathrm{V} / 1000 \mathrm{~W} ; \mathrm{Chl}(\mathrm{mg} / \mathrm{g})=$ $\left(8.02 \mathrm{~A}_{663}+20.21 \mathrm{~A}_{645}\right) \times \mathrm{V} / 1000 \mathrm{~W}$. "V" represented the volume of the extract solution of $25 \mathrm{ml}$, "W" represented the weight of the sampling leaves of $0.2 \mathrm{~g}$.

\section{Measurement of photosynthesis}

photosynthetic rate, stomatal conductance and intercellular $\mathrm{CO}_{2}$ concentration were measured using Li-6400 photosynthesis measurement system. Measurements were taken on the mature leaves of each of the chosen plants.

\section{Measurement of sugar content}

After exposure to salt treatments for 7 days, 15 plants from each treatment (5 per replicate) were sampled to determine sugar content. Sugar content were determined by the anthrone method described by Spiro [70]. $100 \mu \mathrm{l}$ leaf extract were added to $3 \mathrm{ml}$ (final volume) assay media containing $1.08 \mathrm{M} \mathrm{H}_{2} \mathrm{SO}_{4}, 1.09 \mathrm{mM}$ thiourea and $2.1 \mathrm{mM}$ anthrone. The mixture was heated at $100{ }^{\circ} \mathrm{C}$ for $10 \mathrm{~min}$ and absorbance read at $620 \mathrm{~nm}$. A calibration curve with D-glucose was done as a standard.

\section{Total RNA extraction}

Total RNA was isolated from the leaves of sweet sorghum of each genotype treated with 0 and $150 \mathrm{mM} \mathrm{NaCl}$ for $48 \mathrm{~h}$ using a Total Plant RNA Extraction Kit (Karroten, Beijing, China) following the manufacturer's protocols. The RNA was quantified using a Nanodrop ND-1000 spectrophotometer (Thermo Fisher Scientific, Wilmington, DE, USA). A $1 \%$ agarose gel buffered by Tris-acetate-EDTA was also run to determine the integrity of the RNA.

\section{Library construction and Illumina sequencing}

Libraries were constructed following a High Throughput Illumina Strand-Specific RNA Sequencing Library protocol [71]. Briefly, mRNA was purified from $5 \mu \mathrm{g}$ of total 
RNA using oligo (dT) magnetic beads. The purified mRNA was fragmented into small pieces using fragmentation buffer. Taking these short fragments as templates, first-strand cDNA was synthesized using reverse transcriptase and random hexamer primers. Second-strand cDNA synthesis was followed using DNA polymerase I and RNase H. Sequencing adapters were ligated to short fragments after purification with the QiaQuick PCR extraction kit, and which were used to distinguish different sequencing samples. Fragments with different lengths were then separated by agarose gel electrophoresis and selected for PCR amplification as sequencing templates. The final cDNA library was sequenced using Illumina HiSeq $^{\text {TM }} 2500$ at BioMarker Technologies Co Ltd, Beijing. RNA-seq data of the untreated control and salttreated samples were obtained from two and three biological replicates, respectively. The raw reads were cleaned by removing adaptor sequences, empty reads and low quality sequences. Then, clean reads were generated.

\section{Mapping and detection of DEGs}

Clean reads were mapped to the sorghum genome [72, 73] using TopHat version 2.0.10 [74]. Mapping results generated by TopHat were filtered to retain only unique mapped reads before being piped into Cuffdiff (http://cole-trapnell-lab.github.io/cufflinks/) to estimate read counts for each gene. Reads per KB per million (RPKM) values were calculated by an in-house script based on the count table of Cuffdiffs output. The RPKM measure of read density reflects the molar concentration of a transcript in the starting sample by normalizing for RNA length and for the total read number in the measurement. A RPKM threshold value of 0.1 was set to detect the presence of a transcript for a particular gene. DEGs were defined using DESeq [75] as fold changes $\geqq 2$ with a false discovery rate (FDR) adjusted $p$ value $\leq 0.01$.

\section{Gene annotation and classifications}

The optimal assembly results were chosen according to the assembly evaluation. The assembled sequences were compared against the NCBI non-redundant (nr) database [76], Swiss-Prot [77], GO [23], COG [24] and KEGG [25] database using BLAST [78] with E-value $1 \mathrm{e}-10$ as the cutoff. To annotate the assembled sequences with GO terms, the Swiss-Prot BLAST results were imported into Blast2GO [79]. These GO terms were assigned to query sequences, producing a broad overview of groups of genes catalogued in the transcriptome for each of three ontology vocabularies, biological processes, molecular functions [50] and cellular components [23]. The unigenes sequences were also aligned to the COG database to predict and classify functions. KEGG pathways were assigned to the assembled sequences using the online KEGG web server (http://www.genome.jp/ kegg/). The output of KEGG analysis includes KO assignments and KEGG pathways that are populated with the $\mathrm{KO}$ assignments.

\section{Quantitative real-time PCR analysis}

Fourteen DEGs were randomly selected for quantitative real-time PCR to verify the RNA-seq results. Also, three genes which may play important roles in improving sugar content in sweet sorghum were confirmed by qPCR, too. Primers for these 17 genes were designed using the Beacon Designer software (version 7.0) (Additional file 9: Table S2). S. bicolor's housekeeping gene $\beta$-actin (GenBank ID: X79378) was used as an internal standard. $1 \mu \mathrm{g}$ of total RNA was used per $20 \mu \mathrm{l}$ reaction for reverse transcription. Polymerase chain reaction was performed in a $20 \mu \mathrm{l}$ reaction mixture with $10 \mu \mathrm{l}$ SYBR Premix Ex Taq (Bio-RAD, California, USA), $0.5 \mu \mathrm{l}$ of both forward and reverse primers, $7 \mu \mathrm{l}$ of double distilled $\mathrm{H}_{2} \mathrm{O}$ and $2 \mu \mathrm{l}(40 \mathrm{ng} / \mu \mathrm{l})$ of the cDNA. Real-time PCR was performed on a real-time quantitative PCR instrument (Bio-RAD, California, USA). $2^{-\Delta \Delta \mathrm{Ct}}$ method was used to calculate the relative expression of each gene [80].

\section{Statistical analysis}

Multiple comparisons were performed between different samples using Duncan's test at the 0.05 significance level. All tests were performed with SPSS Version 16.0 for Windows (SPSS, Chicago. IL, USA).

\section{Availability of supporting data}

The data sets supporting the results of this article are included within the article and its additional files. The reads produced in this study have been deposited in the National Center for Biotechnology Information (NCBI) SRA database with accession number of SRX1048181, SRX1050048 for M-81E control, SRX1050049, SRX1050050 for M-81E salt-treated, SRX1050054, SRX1050055 for Roma control, and SRX1050056, SRX1050057 for Roma salt-treated. Access to the data is available upon publication at http:// www.ncbi.nlm.nih.gov/sra/.

\section{Additional files}

Additional file 1: Figure S1. Effect of increasing $\mathrm{NaCl}$ concentration on leaf length and leaf number of Roma and M-81E under 3 salt treatments $(0,50$ and $150 \mathrm{mM})$ for 7 days. Values are means \pm SD of five replicates. Bars with the different letters are significantly different at $p=0.05$ according to Duncan's multiple range test.

Additional file 2: Figure S2. Fresh weight, dry weight and water content of $\mathrm{M}-81 \mathrm{E}$ and Roma treated with different concentrations of $\mathrm{NaCl}(0,50$ and $150 \mathrm{mM}$ ) for 7 days. Values are means \pm SD of five replicates. Bars with the different letters are significantly different at $p=0.05$ according to Duncan's multiple range test. Bars with same letter are not significantly different. 
Additional file 3: Figure S3. Concentration of $\mathrm{Na}^{+}, \mathrm{K}^{+}$and the $\mathrm{K}^{+} / \mathrm{Na}^{+}$ ratio in leaves of Roma and M-81E under 3 salt treatments $(0,50$ and $150 \mathrm{mM}$ ) for 7 days. Values are means \pm SD of five replicates. Bars with the different letters are significantly different at $p=0.05$ according to Duncan's multiple range test. Bars with same letter are not significantly different.

Additional file 4: Table S1. Clean reads used for further analysis. Additional file 5: Figure S4. Clusters of orthologous groups (COG) classification.

Additional file 6: Figure S5. KEGG map of the photosynthesis- antenna proteins pathway. It's an analysis of DEGs, comparing salt-treated samples to untreated control. Boxes with a red frame indicate the corresponding DEGs were up-regulated in the salt-treated samples, boxes with a green frame indicate the corresponding DEGs were down-regulated in the salt-treated samples, boxes with blue frame indicate some of the corresponding DEGs were down-regulated and others were up-regulated, and those without any colored frame indicate the expression level of corresponding genes were not changed, as determined by RNA-seq.

Additional file 7: Figure S6. KEGG pathway analysis of the carbon fixation in photosynthetic organisms pathway of M-81E (A) and Roma (B). It's an analysis of DEGs, comparing salt-treated samples to untreated control. The number in each box represents enzyme commission number. Boxes with a red frame indicate the corresponding DEGs were up-regulated in the salt-treated samples, boxes with a green frame indicate the corresponding DEGs were down-regulated in the salt-treated samples, boxes with blue frame indicate some of the corresponding DEGs were down-regulated and others were up-regulated, and those without any colored frame indicate the expression level of corresponding genes were not changed, as determined by RNA-seq.

Additional file 8: Figure S7. KEGG pathway analysis of the starch and sucrose metabolism pathway of M-81E (A) and Roma (B). It's an analysis of DEGs, comparing salt-treated samples to untreated control. The number in each box represents enzyme commission number. Boxes with a red frame indicate the corresponding DEGs were up-regulated in the salt-treated samples, boxes with a green frame indicate the corresponding DEGs were down-regulated in the salt-treated samples, boxes with blue frame indicate some of the corresponding DEGs were down-regulated and others were up-regulated, and those without any colored frame indicate the expression level of corresponding genes were not changed, as determined by RNA-seq.

Additional file 9: Table S2. Table S2 Primer pairs for real-time quantitative PCR.

\section{Abbreviations}

OAA: Oxaloacetate; TP: Triose phosphate; TPT: Triose phosphate translocator; SPS: Sucrose phosphate phosphatase; SS: Synthase; INV: Invertase; SUT: Sucrose transporters; FW: Fresh weights; DW: Dry weight; WC: Water content; NADP-ME: NADP+'-malate enzyme; RNA-seq: RNA-sequencing; DEGs: Differentially expressed genes; RPKM: Reads per KB per million; FDR: False discovery rate; GO: Gene ontology; COG: Clusters of orthologous groups; KEGG: Kyoto encyclopedia of genes and genomes; LHCs: Light-harvesting complexes; rubisco: Ribulose-bisphosphate carboxylase; PEPC: Phosphoenolpyruvate carboxylase; PPDK: Pyruvate orthophosphate dikinase.

\section{Competing interests}

The authors declare that they have no competing interests.

\section{Authors' contributions}

$Z Y$ wrote this manuscript; ZY and ML performed experiments; NS and ZY collected data and carried out all analyses; NS and BW conceptualized the idea. All authors read and approved the final manuscript.

\section{Acknowledgements}

We are grateful for financial support from the NSFC (National Natural Science Research Foundation of China (31300205), Programs Foundation of Ministry of Education of China (20123704130001), Natural Science Research Foundation of Shandong (ZR2013CQ009), the Science and Technology
Development Projects of Shandong Province (2014GNC113005) and the Program for Scientific research innovation team in colleges and universities of Shandong Province.

Received: 9 March 2015 Accepted: 7 July 2015 Published online: 19 July 2015

\section{References}

1. Zhu JK. Plant salt tolerance. Trends Plant Sci. 2001;6(2):66-71.

2. Hasegawa PBR, Zhu J, Bohnert H. Plant cellular and molecular responses to high salinity. Annu Rev Plant Physiol Plant Mol Biol. 2000;51:463-99.

3. Carillo P, Annunziata MG, Pontecorvo G, Fuggi A, Woodrow P. Salinity stress and salt tolerance. 2011.

4. Zhifang G, Loescher WH. Expression of a celery mannose 6-phosphate reductase in Arabidopsis thaliana enhances salt tolerance and induces biosynthesis of both mannitol and a glucosyl-mannitol dimer. Plant Cell Environ. 2003;26(2):275-83.

5. Shi H, Lee Bh WSJ, Zhu JK. Overexpression of a plasma membrane $\mathrm{Na}^{+} / \mathrm{H}^{+}$ antiporter gene improves salt tolerance in Arabidopsis thaliana. Nat Biotech. 2003;21(1):81-5.

6. Kasuga M, Liu Q, Miura S, Yamaguchi-Shinozaki K, Shinozaki K. Improving plant drought, salt, and freezing tolerance by gene transfer of a single stress-inducible transcription factor. Nat Biotech. 1999;17(3):287-91.

7. Almodares A, Hadi M. Production of bioethanol from sweet sorghum: A review. Afr J Agric Res. 2009:4(9):772-80.

8. Gnansounou E, Dauriat A, Wyman C. Refining sweet sorghum to ethanol and sugar: economic trade-offs in the context of North China. Bioresour Technol. 2005;96(9):985-1002

9. Dai LY, Zhang L, Jiang SJ, Yin KD. Saline and alkaline stress genotypic tolerance in sweet sorghum is linked to sodium distribution. Acta Agric Scand Sec B Soil Plant Sci. 2014;64(6):471-81.

10. Fan H, Wu HD, Zhou ML, Zhang Y, Ding TL, Wang BS. Planting sweet sorghum in Yellow River delta: the cultivation measure, yield and effect on soil microflora. Adv Mater Res. 2012;518:81-7.

11. Ding TL, Song J, Guo JR, Sui N, Fan H, Chen M, et al. The cultivation technique for increasing the stalk sugar content of energy plant sweet sorghum in Yellow River delta. Adv Mat Res. 2013;724:437-42.

12. Vasilakoglou I, Dhima K, Karagiannidis N, Gatsis T. Sweet sorghum productivity for biofuels under increased soil salinity and reduced irrigation. Field Crop Res. 2011;120(1):38-46.

13. Gowik U, Bräutigam A, Weber KL, Weber AP, Westhoff P. Evolution of C4 photosynthesis in the genus Flaveria: how many and which genes does it take to make C4? Plant Cell Online. 2011;23(6):2087-105.

14. Flügge UI. Phosphate translocators in plastids. Annu Rev Plant Biol. 1999;50(1):27-45

15. Braun DM, Slewinski TL. Genetic control of carbon partitioning in grasses: roles of sucrose transporters and tie-dyed loci in phloem loading. Plant Physiol. 2009;149(1):71-81.

16. Sauer N. Molecular physiology of higher plant sucrose transporters. FEBS Lett. 2007;581(12):2309-17.

17. Kalaitzis $P$, Bazakos C, Manioudaki M. Comparative transcriptome analysis of two olive cultivars in response to NaCl-stress. PLoS One. 2012;7(8):e42931.

18. Walia $\mathrm{H}$, Wilson C, Condamine P, Liu X, Ismail AM, Zeng L, et al. Comparative transcriptional profiling of two contrasting rice genotypes under salinity stress during the vegetative growth stage. Plant Physiol. 2005;139(2):822-35.

19. Wang Y, Yang L, Zheng Z, Grumet R, Loescher W, Zhu JK, et al. Transcriptomic and physiological variations of three arabidopsis ecotypes in response to salt stress. PLoS One. 2013;8(7):e69036.

20. Walia H, Wilson C, Zeng L, Ismail AM, Condamine P, Close TJ. Genome-wide transcriptional analysis of salinity stressed japonica and indica rice genotypes during panicle initiation stage. Plant Mol Biol. 2007;63(5):609-23.

21. Beritognolo I, Harfouche A, Brilli F, Prosperini G, Gaudet M, Brosché M, et al. Comparative study of transcriptional and physiological responses to salinity stress in two contrasting Populus alba L. genotypes. Tree Physiol. 2011;31(12):1335-55. doi:10.1093/treephys/tpr083.

22. Sun W, Xu X, Zhu H, Liu A, Liu L, Li J, et al. Comparative transcriptomic profiling of a salt-tolerant wild tomato species and a salt-sensitive tomato cultivar. Plant Cell Physiol. 2010;51(6):997-1006.

23. Ashburner M, Ball CA, Blake JA, Botstein D, Butler H, Cherry JM, et al. Gene ontology: tool for the unification of biology. Nat Genet. 2000;25(1):25-9. 
24. Tatusov RL, Galperin MY, Natale DA, Koonin EV. The COG database: a tool for genome-scale analysis of protein functions and evolution. Nucleic Acids Res. 2000;28(1):33-6.

25. Kanehisa M, Goto S, Kawashima S, Okuno Y, Hattori M. The KEGG resource for deciphering the genome. Nucleic Acids Res. 2004;32 suppl 1:D277-80.

26. van Amerongen $H$, van Grondelle $R$. Understanding the energy transfer function of LHCII, the major light-harvesting complex of green plants. J Phys Chem B. 2001;105(3):604-17.

27. Galka P, Santabarbara S, Khuong TTH, Degand H, Morsomme P, Jennings $\mathrm{RC}$, et al. Functional analyses of the plant photosystem I-light-harvesting complex II supercomplex reveal that light-harvesting complex I| loosely bound to photosystem II is a very efficient antenna for photosystem I in state II. Plant Cell Online. 2012;24(7):2963-78.

28. Green BR, Pichersky E, Kloppstech K. Chlorophyll a/b-binding proteins: an extended family. Trends Biochem Sci. 1991;16:181-6.

29. Klimmek F, Sjödin A, Noutsos C, Leister D, Jansson S. Abundantly and rarely expressed Lhc protein genes exhibit distinct regulation patterns in plants. Plant Physiol. 2006;140(3):793-804.

30. Moradi F, Ismail AM. Responses of photosynthesis, chlorophyll fluorescence and ROS-scavenging systems to salt stress during seedling and reproductive stages in rice. Ann Bot. 2007;99(6):1161-73.

31. Sudhir P, Murthy S. Effects of salt stress on basic processes of photosynthesis. Photosynthetica. 2004;42(2):481-6.

32. Wydrzynski TJ. Water splitting by Photosystem II-where do we go from here? Photosynth Res. 2008;98(1-3):43-51.

33. Summerfield TC, Shand JA, Bentley FK, Eaton-Rye JJ. PsbQ (SII1638) in Synechocystis sp. PCC 6803 is required for photosystem II activity in specific mutants and in nutrient-limiting conditions. Biochemistry. 2005;44(2):805-15.

34. Thornton LE, Ohkawa H, Roose JL, Kashino Y, Keren N, Pakrasi HB. Homologs of plant PsbP and PsbQ proteins are necessary for regulation of photosystem II activity in the cyanobacterium Synechocystis 6803. Plant Cell Online. 2004;16(8):2164-75.

35. Suorsa M, Sirpiö S, Allahverdiyeva Y, Paakkarinen V, Mamedov F, Styring S, et al. PsbR, a missing link in the assembly of the oxygen-evolving complex of plant photosystem II. J Biol Chem. 2006;281(1):145-50.

36. Scheller HV, Naver H, Møller BL. Molecular aspects of photosystem I. Physiol Plant. 1997;100(4):842-51.

37. Knoetzel J, Mant A, Haldrup A, Jensen PE, Scheller HV. PSI-O, a new 10-kDa subunit of eukaryotic photosystem I. FEBS Lett. 2002;510(3):145-8.

38. Yadavalli V, Malleda C, Subramanyam R. Protein-protein interactions by molecular modeling and biochemical characterization of PSI-LHCI supercomplexes from Chlamydomonas reinhardtii. Mol Biosyst. 2011;7(11):3143-51.

39. Jensen PE, Gilpin M, Knoetzel J, Scheller HV. The PSI-K subunit of photosystem I is involved in the interaction between light-harvesting complex I and the photosystem I reaction center core. J Biol Chem. 2000;275(32):24701-8.

40. Chitnis PR. Photosystem I. Plant Physiol. 1996;111(3):661.

41. Haldrup A, Naver H, Scheller HV. The interaction between plastocyanin and photosystem I is inefficient in transgenic Arabidopsis plants lacking the PSI-N subunit of photosystem. Plant J. 1999;17(6):689-98.

42. Whitney SM, Houtz RL, Alonso H. Advancing our understanding and capacity to engineer nature's CO2-sequestering enzyme, Rubisco. Plant Physiol. 2011;155(1):27-35.

43. Hoffmann Thoma G, Hinkel K, Nicolay P, Willenbrink J. Sucrose accumulation in sweet sorghum stem internodes in relation to growth. Physiol Plant. 1996;97(2):277-84.

44. Sunseri F, Palazzo D, Montemurro N, Montemurro F. Salinity tolerance in sweet sorghum (Sorghum bicolor L. Moench): Field performance under salt stress. Ital J Agron. 1998;2:111-6.

45. Blumwald E. Sodium transport and salt tolerance in plants. Curr Opin Cell Biol. 2000;12(4):431-4.

46. Tester $\mathrm{M}$, Davenport $\mathrm{R} . \mathrm{Na}^{+}$tolerance and $\mathrm{Na}^{+}$transport in higher plants. Ann Bot. 2003;91(5):503-27.

47. Munns R, Tester M. Mechanisms of salinity tolerance. Annu Rev Plant Biol. 2008:59:651-81.

48. Carden DE, Walker DJ, Flowers TJ, Miller AJ. Single-cell measurements of the contributions of cytosolic $\mathrm{Na}^{+}$and $\mathrm{K}^{+}$to salt tolerance. Plant Physiol. 2003;131(2):676-83.

49. Taji T, Seki M, Satou M, Sakurai T, Kobayashi M, Ishiyama K, et al. Comparative genomics in salt tolerance between Arabidopsis and
Arabidopsis-related halophyte salt cress using Arabidopsis microarray. Plant Physiol. 2004;135(3):1697-709.

50. García-Legaz M, Ortiz J, Garcí-Lidón A, Cerda A. Effect of salinity on growth, ion content and $\mathrm{CO} 2$ assimilation rate in lemon varieties on different rootstocks. Physiol Plant. 1993;89(3):427-32.

51. James RA, Rivelli AR, Munns R, von Caemmerer S. Factors affecting $\mathrm{CO}_{2}$ assimilation, leaf injury and growth in salt-stressed durum wheat. Funct Plant Biol. 2002;29(12):1393-403.

52. Plaut Z, Federman E. Acclimation of $\mathrm{CO}_{2}$ assimilation in cotton leaves to water stress and salinity. Plant Physiol. 1991;97(2):515-22.

53. Yang X, Liang Z, Wen X, Lu C. Genetic engineering of the biosynthesis of glycinebetaine leads to increased tolerance of photosynthesis to salt stress in transgenic tobacco plants. Plant Mol Biol. 2008;66(1-2):73-86.

54. Rothermel BA, Nelson T. Primary structure of the maize NADP-dependent malic enzyme. J Biol Chem. 1989;264(33):19587-92.

55. Chang GG, Tong L. Structure and function of malic enzymes, a new class of oxidative decarboxylases. Biochemistry. 2003;42(44):12721-33.

56. Sun SB, Shen QR, Wan JM, Liu ZP. Induced expression of the gene for NADP-malic enzyme in leaves of Aloe vera L. under salt stress. Acta Biochim Biophys Sinica Chin Ed. 2003;35(5):423-9.

57. Liu S, Cheng Y, Zhang X, Guan Q, Nishiuchi S, Hase K, et al. Expression of an NADP-malic enzyme gene in rice (Oryza sativa. L) is induced by environmental stresses; over-expression of the gene in Arabidopsis confers salt and osmotic stress tolerance. Plant Mol Biol. 2007;64(1-2):49-58.

58. Casati P, Drincovich MF, Edwards GE, Andreo CS. Malate metabolism by NADP-malic enzyme in plant defense. Photosynth Res. 1999;61(2):99-105.

59. Cheng $Y$, Long M. A cytosolic NADP-malic enzyme gene from rice (Oryza sativa L.) confers salt tolerance in transgenic Arabidopsis. Biotechnol Lett. 2007;29(7):1129-34.

60. Meloni DA, Oliva MA, Martinez CA, Cambraia J. Photosynthesis and activity of superoxide dismutase, peroxidase and glutathione reductase in cotton under salt stress. Environ Exp Bot. 2003;49(1):69-76.

61. Xiong L, Schumaker KS, Zhu JK. Cell signaling during cold, drought, and salt stress. Plant Cell Online. 2002;14 suppl 1:S165-83.

62. Lin $\mathrm{CC}$, $\mathrm{Kao} \mathrm{CH}$. Effect of $\mathrm{NaCl}$ stress on $\mathrm{H}_{2} \mathrm{O}_{2}$ metabolism in rice leaves. Plant Growth Regul. 2000;30(2):151-5.

63. Mittler R. Oxidative stress, antioxidants and stress tolerance. Trends Plant Sci. 2002;7(9):405-10.

64. Møller IM, Rasmusson AG. The role of NADP in the mitochondrial matrix. Trends Plant Sci. 1998:3:21-27.

65. Qazi HA, Paranjpe S, Bhargava S. Stem sugar accumulation in sweet sorghum-activity and expression of sucrose metabolizing enzymes and sucrose transporters. J Plant Physiol. 2012;169(6):605-13.

66. Whittaker A, Botha FC. Carbon partitioning during sucrose accumulation in sugarcane internodal tissue. Plant Physiol. 1997;115(4):1651-9.

67. Gong X, Liu M, Zhang L, Ruan Y, Ding R, Ji Y, et al. Arabidopsis AtSUC2 and AtSUC4, encoding sucrose transporters, are required for abiotic stress tolerance in an ABA-dependent pathway. Physiol Plant. 2015;153(1):119-36.

68. Kooten O, Snel JF. The use of chlorophyll fluorescence nomenclature in plant stress physiology. Photosynth Res. 1990;25(3):147-50.

69. Arnon DI. Copper enzymes in isolated chloroplasts, polyohenoloxidase in beta vulgaris. Plant Physiol. 1949;24(1):1-15.

70. Spiro RG. Analysis of sugars found in glycoproteins. Methods Enzymol. 1966:8:3-26.

71. Zhong S, Joung JG, Zheng Y, Chen Y, Liu B, Shao Y, et al. High-throughput illumina strand-specific RNA sequencing library preparation. Cold Spring Harb Protoc. 2011;2011(8):940-9. doi:10.1101/pdb.prot5652.

72. Zheng LY, Guo XS, He B, Sun LJ, Peng Y, Dong SS, et al. Genome-wide patterns of genetic variation in sweet and grain sorghum (Sorghum bicolor). Genome Biol. 2011;12(11):R114.

73. Paterson AH, Bowers JE, Bruggmann R, Dubchak I, Grimwood J, Gundlach H, et al. The Sorghum bicolor genome and the diversification of grasses. Nature. 2009;457(7229):551-6.

74. Trapnell C, Pachter L, Salzberg SL. TopHat: discovering splice junctions with RNA-seq. Bioinformatics (Oxford, England). 2009;25(9):1105-11.

75. Anders S, Huber W. Differential expression analysis for sequence count data. Genome Biol. 2010;11(10):R106.

76. Pruitt KD, Tatusova T, Maglott DR. NCBI Reference Sequence (RefSeq): a curated non-redundant sequence database of genomes, transcripts and proteins. Nucleic Acids Res. 2005;33 suppl 1:D501-4. 
77. Apweiler R, Bairoch A, Wu CH, Barker WC, Boeckmann B, Ferro S, et al. UniProt: the universal protein knowledgebase. Nucleic Acids Res. 2004;32(Database issue):D115-119.

78. Altschul SF, Madden TL, Schaffer AA, Zhang J, Zhang Z, Miller W, et al. Gapped BLAST and PSI-BLAST: a new generation of protein database search programs. Nucleic Acids Res. 1997;25(17):3389-402

79. Conesa A, Götz S, García-Gómez JM, Terol J, Talón M, Robles M. Blast2GO: a universal tool for annotation, visualization and analysis in functional genomics research. Bioinformatics (Oxford, England). 2005;21(18):3674-6.

80. Livak KJ, Schmittgen TD. Analysis of relative gene expression data using real-time quantitative $P C R$ and the $2-\Delta \Delta C T$ method. Methods. 2001;25(4):402-8.

\section{Submit your next manuscript to BioMed Central} and take full advantage of:

- Convenient online submission

- Thorough peer review

- No space constraints or color figure charges

- Immediate publication on acceptance

- Inclusion in PubMed, CAS, Scopus and Google Scholar

- Research which is freely available for redistribution 